DOI: 10.1590/permusi2015a3102

\title{
Gesto na performance da percussão, Parte 1: análise percentual de dados experimentais ${ }^{1}$
}

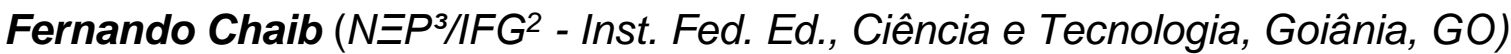
fernandochaib@gmail.com

Homero Chaib Filho (N三P/IFG3 - Inst. Fed. Ed., Ciência e Tecnologia, Goiânia, GO)

homerochaibfilho@gmail.com

\author{
João Catalão (SIxtrum/Université de Montreal, Montreal, Canadá) \\ catalao@ktzperc.com
}

Resumo: Este artigo, Parte 1 do mesmo estudo, mostra como foi realizado um tratamento descritivo, através de uma análise percentual, dos dados experimentais obtidos ao observar a influência do gesto corporal sobre as sensações de continuidade, suspensão e conclusão de um trecho musical em percussão. Dentro da complexa relação estabelecida entre o percussionista e o texto musical apresentado em grande parte das produções para percussão, procuramos compreender até que ponto o corpo poderá ser um agente auxiliador no processo de transmissão de sensações específicas sobre a música executada em uma performance percussiva. A complexidade deste processo experimental nos obrigou a dividir os resultados obtidos em dois artigos. Este trabalho trata-se da $1^{\text {a }}$ parte de publicação dos dados adquiridos e analisados a partir dos pesos percentuais.

Palavras-chave: influência do gesto na Performance; percussão; performance; estatística descritiva.

\section{Gestures on percussion performance, Part 1: percentage analysis of experimental data}

\begin{abstract}
This paper, Part 1 of the same study, discusses the influence of corporal gesture on the sensations of continuity, suspension and conclusion of a percussion musical excerpt from a descriptive statistical analysis data obtained on a specific experiment. From the complex relationship between the percussionist and musical text displayed largely on percussion productions, we seek to understand how far the motion body could be a supportive agent in the process of transmission of specific feelings about the music performed in a percussive performance. The complexity of this experimental process forced us to divide the results into two articles. This work comes from the 1st part of publishing data acquired since the experiment exposed here also suffered a factorial analysis of correspondences, can be found in the subsequent Article from this one ".
\end{abstract}

Keywords: gesture influence in performance; percussion; descriptive statistic.

1. Introdução - Considerando as relações do movimento corporal, exercício intelectual e expressividade expostas no artigo "Três Perspectivas Gestuais para uma Performance Percussiva: Técnica, Interpretativa e Expressiva" (CHAIB, 2012), nos indagamos em como os gestos, direcionados a uma ação performativa percussiva, poderiam atuar sobre as sensações de determinados conteúdos musicais transmitidos ao espectador. Observadas e discutidas as potencialidades 
do gesto vinculadas à performance em percussão (CHAIB, 2012), nos concentramos essencialmente neste artigo em determinar de que maneira esse elemento performativo poderá exercer influência sobre a percepção de um trecho musical no repertório dedicado à música para percussão, mais precisamente sobre as sensações continuidade, suspensão e conclusão de um individuo ao assistir a performance de um percussionista.

Nesta primeira parte de publicação dos dados adquiridos e analisados através do experimento "Sensação de continuidade de um trecho musical" 4 , procuramos identificar certos níveis de influência dos gestos (e suas atitudes ${ }^{5}$ ) sobre a transmissão do conteúdo musical, realizados pelo percussionista durante uma performance. Para a compreensão dos resultados, utilizamos primeiramente uma análise estatística em termos percentuais que, a grosso modo, expressa o peso de cada resultado às questões propostas no experimento realizado. A segunda parte de publicação dos resultados estará disponível no artigo subsequente a este.

2. Problemática - Nossa problemática baseou-se fundamentalmente na transmissão de diferentes ou similares conteúdos musicais a partir da execução de distintos instrumentos de percussão (tendo em conta as características tímbricas e sonoras de cada um), em conformidade com o texto musical apresentado na partitura. Ou seja, de que modo o percussionista poderia determinar, em uma caixa por exemplo, a diferença de valores de tempo existentes entre duas figuras rítmicas distintas, uma vez que por questões físicas e características do instrumento o resultado sonoro será essencialmente o mesmo. llustramos esse questionamento no exemplo a seguir (Ex.1):

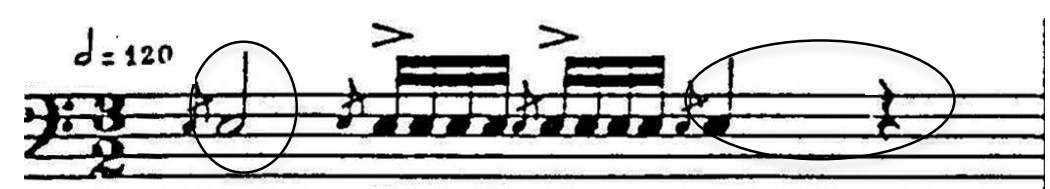

Ex.1 - Suite for Drums (SMITH, 1940). Percussionista 2, c.71.

Considerando os atributos sonoros e tímbricos de uma caixa percebermos ser praticamente impossível conseguirmos transmitir sonoramente as diferentes ideias ilustradas no $1^{\circ}$ e $3^{\circ}$ tempo do Ex.1 (mínima; semínima e pausa de semínima). Percebemos que a ideia a ser passada de prolongamento da nota (mínima) ou de ausência de intervenção sonora do intérprete ${ }^{6}$ (pausa de semínima) torna-se um desafio. Um dos caminhos que o percussionista poderá seguir para encontrar soluções sobre essa questão passará por atuar sobre o instrumento utilizando-se de meios menos ortodoxos relativamente à estética de composição utilizada (abafar o som da caixa na pausa de semínima utilizando as mãos sobre a pele ou qualquer outro meio de abafamento). No entanto, ao analisarmos o estilo da obra somos levados a considerar em Ex.1 um tipo de execução tradicional, utilizando apenas a baqueta sobre a pele. Desta forma a transmissão dessa diferenciação rítmica, se possível, deverá ser desenvolvida a partir de outras formas.

Em geral, o percussionista apenas utiliza métodos distintos ao uso das baquetas (considerando a via tradicional de extração sonora do instrumento em questão) 
quando estes são requeridos pelo compositor e/ou estipulados na partitura. Portanto, se não há indicação de intervenção do percussionista sobre o som da caixa através de outros meios, diremos que a mínima e a semínima soarão de forma semelhante (se não mesmo idêntica), pois que a caixa não possui mecanismos para o controle do tempo de decaimento de uma nota (como por exemplo o pedal de um vibrafone, sinos tubulares ou outras técnicas de abafamento). Poderá ser compreensível e bem clara a ideia do compositor, mas transmiti-la através da caixa torna o caminho interpretativo do percussionista um processo complexo e intrigante. Essa é uma contrariedade à qual, relativamente ao repertório existente para percussão, o intérprete vê-se submergido quase que a tempo inteiro.

Outro exemplo que cabe perfeitamente nesse objeto de pesquisa será a relação em uma obra que se faz entre textos musicais semelhantes executados em diferentes instrumentos de percussão. Um instrumento de lâminas e um de pele possuem características bastante distintas quer seja no aspecto sonoro, material e/ou estrutural, pelo quê torna-se um desafio para o percussionista transmitir ideias musicais análogas a partir dos dois instrumentos. Observando obras escritas em fins do séc. XX encontramos em Phènix (1982), de Bernard-Mâche, um exemplo que bem se adequa a essa discussão (Exs.2 e 3):

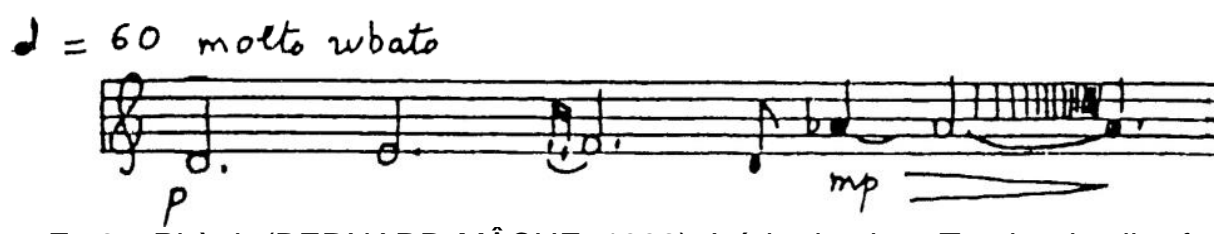

Ex.2 - Phènix (BERNARD-MÂCHE, 1982): Início da obra. Trecho do vibrafone.

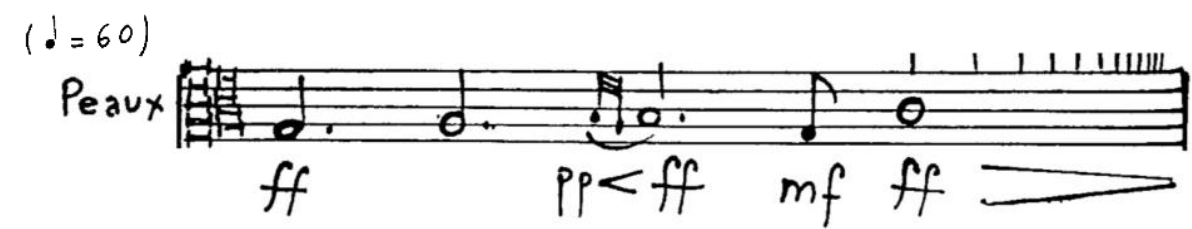

Ex.3 - Phènix (BERNARD-MÂCHE, 1982: 02). Início do 1ํo sistema. Trecho das peles.

Em Ex.2 e Ex.3 o sentido do texto musical análogo segue um caminho quase utópico. Será forçoso o desenvolvimento de outros atributos performativos que permitam ao intérprete aproximar a mesma ideia musical presente na partitura para estes instrumentos. O movimento corporal, através dos gestos passíveis de serem realizados pelo percussionista durante uma performance, poderá ser esse catalisador de ideias entre som e conteúdo musical que buscamos. A questão metafórica do gesto aplicada à música escrita para percussão poderá encaixar-se nesse exemplo, auxiliando o intérprete na transmissão do conteúdo musical. A simbologia dos valores de tempo transmitida pelo corpo poderá compor a metáfora desse momento musical e performativo, gerando outros atributos interpretativos e expressivos em palco em conjunção com o fenômeno sonoro. 
Diversos exemplos poderão ser utilizados para percebermos como textos musicais apresentados em obras escritas para percussão colocam, em geral, o percussionista em uma encruzilhada interpretativa complexa. Essa busca por uma performance com o intuito de ilustrar toda a expressividade em conformidade com - conteúdo musical da composição executada torna-se, por muitas vezes, bastante difícil, uma vez que a relação interpretativa da obra estabelecida entre o performer e o espectador é sujeita a diversos níveis de subjetividade.

Perceber a existência da influência do movimento corporal, através dos gestos, sobre a transmissão do conteúdo musical, para o espectador, poderá servir de auxílio no desenvolvimento de uma géstica performativa para o percussionista em palco. Isso significa essencialmente gerar mecanismos e ferramentas de cunho gestual para que o intérprete pluralize as suas possibilidades em ilustrar e transmitir as ideias musicais contidas na partitura, tendo em conta as particularidades sonoras, tímbricas e possibilidades de expressão presentes nos instrumentos de percussão.

3. Pesquisas no campo - Através do estilo de experimentação cross-modal interaction $^{7}$, experiências com apresentação conjunta de diferentes estímulos realizada por MCGURK e MCDONALD (1976) comprovaram a influência da visão sobre a percepção auditiva, classificando o fenómeno como "Efeito McGurk". Esse tipo de experimentação consiste em cruzar diferentes tipos de sensações (auditivas, visuais, tácteis, etc.) com o intuito de perceber-se os níveis de influência de um estímulo sobre o outro. No caso de McGurk e McDonald os estímulos visual e auditivo apresentados correspondiam a uma pessoa pronunciando as sílabas "ga" e "ba". A experiência consistiu em apresentar os dois estímulos com as informações cruzadas no formato audiovisual. Foi constatado pelos investigadores que, para além das respostas não condizerem com a imagem e o seu som respectivo, os participantes apresentaram a sensação de uma terceira sílaba inexistente ("da"), atestando assim a influência do aspecto visual sobre as informações sonoras passadas ${ }^{8}$. SALDAÑA e ROSENBAUM (1993) redimensionaram o "Efeito McGurk" (também utilizando o tipo de experimentação cross-modal interaction) para eventos sonoros não vocais, ao realizarem experimento com violoncelo e constatarem a influência do estímulo visual sobre o timbre do instrumento ao ser executado com arco ou com os dedos (pizzicato).

LERDHAL e JACKENDO (1983) relacionaram as aplicações das leis da Gestalt ao processo de segmentação das frases musicais dentro da música tonal apresentando-nos as regras de proximidade (proximity rules). Duas regras são relacionadas pelos autores: 'pausa ou nota longa' (s/ur or rest) e ponto de ataque (atack-point) ou momento exato da extração sonora do instrumento. Ao redimensionarmos o caráter de observação do conteúdo musical para o repertório percussivo conseguimos encontrar certas concordâncias. Uma delas refere-se ao Ex.1 onde a primeira regra de proximidade enquadra-se de forma clara. Já os Ex.2 e Ex.3 referenciam as regras de mudança (change rules) onde enquadramse as relações de registo (altura), dinâmica (volume), articulação, timbre e comprimento. 
Pertencendo a um mesmo campo de investigação, os trabalhos acerca do gesto em percussão carregam diferentes abordagens relativas ao objeto de pesquisa. Antecipando-se à gama de estudos existentes, BAILEY (1963) já procurava discutir (ou pelo menos demonstrar) certas problemáticas evidentes na performance para percussão ao destacar que o percussionista, quando desejado, deveria desenvolver técnicas capazes de transmitirem sensações de legato, mesmo sendo impossível conseguir esse efeito no próprio sentido da palavra.

As discussões que buscam encontrar soluções para os identificáveis desafios impostos pelos instrumentos de percussão sob a interpretação e expressão musical do intérprete são, de fato, bastante correntes no universo percussivo. Para além dos recursos expressivos como legato, stacato, tenuto, etc., a partir do momento em que as produções para percussão foram se desenvolvendo, as discrepâncias de timbre e técnica tornaram-se fatores que criaram maiores níveis de complexidade para a busca do percussionista por uma execução musical condizente com o texto (e/ou discurso) musical apresentado na partitura.

Relativamente às pesquisas existentes sobre as influências da aplicação do gesto em uma performance destinada aos instrumentos de percussão, percebemos que diversos trabalhos foram realizados durante a primeira década deste século, ainda que sob perspectivas distintas da utilização e possibilidades gestuais na performance percussiva. Dentre os trabalhos existentes destacamos SCHUTZ e LIPSCOMB (2004). Os autores realizaram um experimento onde a intenção era verificar a percepção da articulação do toque sobre a marimba. Para tanto utilizaram 0 estilo de experimentação cross-modal interaction, realizando diferentes intenções gestuais. Diferentemente de McGurk e McDonald, a correlação da expressão facial com sílabas foi substituída pela relação do movimento corporal com certos meios expressivos a serem obtidos da marimba.

Schutz e Lipscomb procuraram demonstrar as relações de toques em meios expressivos específicos. Foram escolhidas quatro níveis de expressão: staccato, abafado, normal e legato. Os estímulos, gravados em áudio e áudio/vídeo, foram apresentados a 70 participantes divididos em 3 grupos com distintas habilidades musicais. Uma escala com valores de 0 (máximo staccato) a 100 (máximo legato) foi apresentada. Com o auxílio de um cursor, os indivíduos apontaram no computador a sua sensação relacionada aos estímulos expostos. Durante as análises de resultados verificou-se que as informações transmitidas pelo gesto do percussionista faziam os participantes alterarem as percepções do som, sendo que o mesmo não correspondia à realidade das respostas.

DAHL (2005) realizou um experimento onde a marimba também foi utilizada como instrumento. Foi solicitado a um percussionista profissional executar uma pequena obra tendo em conta os sentimentos tristeza, raiva, alegria e medo. Os vídeos foram apresentados a 20 indivíduos de quatro maneiras distintas: exibindo o corpo inteiro do percussionista, exibindo apenas as mãos, exibindo apenas o tronco (sem mãos e cabeça) e exibindo apenas a cabeça. Os participantes deveriam responder àquelas sensações numa escala de 0 (nada) a 6 (muito). 
Considerando os resultados obtidos, a autora chegou à conclusão de que a influência visual foi "surpreendentemente pequena" em relação às respostas dadas e os vídeos demonstrados com os diferentes sentimentos.

Contudo, não nos interessa aqui atribuir valores de juízo sentimentais aos estados emocionais em que poderão se encontrar os participantes do experimento que exporemos mais adiante. As formas como os indivíduos se comportam ou expressam seus momentos mais ou menos afetivos pode variar de tal forma (por questões culturais, educativos, etc.) que colocaria em risco o nosso objetivo que é o de identificar a influência no espectador do gesto na transmissão de um trecho musical percussivo. O nosso interesse gira em torno da música e da sua relação com o espectador, no aspecto interpretativo, obtido através da performance do percussionista em consequência dos movimentos corporais aplicados. Não nos cabe (e nem é nossa intenção) induzir o indivíduo a estados emocionais aos quais o intérprete possa estar conectado com a obra.

WANDERLEY et. al. (2005) efetuaram um estudo sobre as informações visuais e auditivas através de uma performance musical (nesse caso utilizando a performance sobre o clarinete), concentrando as informações visuais sobre a percepção da estrutura da obra. O registo dos estímulos ocorreu em áudio, vídeo e áudio/vídeo, sendo as respostas dos participantes gravadas em tempo real, durante o tempo de duração da exibição dos estímulos. Para a análise de dados utilizaram a técnica estatística functional data analysis ${ }^{9}$. Esta técnica trata os dados obtidos em funções matemáticas contínuas o que, segundo os autores, permite questionar os níveis de impacto sobre o julgamento das tensões atribuídas à performance estando ela ora relacionada a uma componente visual e ora não relacionada; o que também se distancia do objetivo do nosso trabalho. Ao contrário de outras técnicas estatísticas utilizadas em experimentos em música (onde os dados são tratados apenas por uma dimensão individualizando as respostas dos participantes), o functional data analysis permite obter uma imagem dos resultados em três dimensões, estabilizando problemas como a sincronização e correlação entre as respostas dos diferentes participantes.

No que diz respeito às técnicas utilizadas por percussionistas (em específico sobre os tímpanos), BOUENARD, WANDERLEY e GIBET (2009) mapearam, utilizando dois timpanistas, as diferentes relações existentes entre duas técnicas distintas (alemã e francesa) aplicadas sobre o tímpano e o som obtido no instrumento. Foram capazes de observar que os diferentes gestos utilizados sobre as duas técnicas modificavam o resultado sonoro final.

Dentre outras concepções discutidas no decorrer do nosso trabalho procuramos utilizar como referência o conceito de sound-accompanying gestures, onde o mesmo é estabelecido por GODØY (2010, p.110) como: "all kinds of body movements that may be made to music [...] not necessary to produce the sound". Nos direcionando para o repertório percussivo, numa visão global, as diferentes ideias de movimento poderão estar, eventualmente, sincronizadas com os eventos sonoros ocorridos na performance e serão capazes de auxiliar o intérprete a transmitir para o público os conteúdos do discurso musical proposto 
pela obra. Será dizer que os gestos realizados pelo percussionista durante uma performance poderão influenciar a percepção do texto musical sobre o receptor dessa informação. A ideia é sugerir a criação de mecanismos técnicos, interpretativos e expressivos que amenizem as limitações encontradas por percussionistas perante os diferentes instrumentos de percussão para a busca de uma expressividade musical congruente e, possivelmente, mais fiel às ideias musicais propostas pelo compositor em uma determinada obra. Alargar a ideia de Godøy será de fundamental importância para não nos limitarmos apenas a exercer os movimentos corporais vinculados ao som realizado, sistematizando uma ação que, no nosso entender, é subjetiva e passível de inúmeras interpretações. Uma vez que os instrumentos de percussão possuem capacidades de extração sonora e ressonância muito distintas, diremos que o principal intuito será o de relacionar os movimentos corporais à ideia musical exposta na partitura e perceber de que maneira isso causará influência no indivíduo que observa a performance.

Para comprovarmos a influência da percepção sobre um trecho musical através do gesto corporal aplicado no repertório percussivo, coletamos dados das sensações de indivíduos perante a execução de três excertos musicais de uma obra em específico. Para isso alternamos, nos estímulos exibidos, gestos sobre diferentes perspectivas, permitindo determinar o grau de influência dos mesmos sobre a informação musical passada. Para GODØY (2011, p.71), os gestos: "could be regarded as integral to music perception, leading to the idea that any sound will be included in some mental image of a gestural trajectory".

\section{Elaboração do Experimento "Sensação de continuidade de um} trecho musical" - Através da realização do experimento "Sensação de continuidade de um trecho musical" coletamos as primeiras reações de um indivíduo relativamente a uma performance em percussão. Reproduzimos três excertos musicais a um grupo de indivíduos - transmitidos a partir de estímulos visual (V); auditivo (A); audiovisual (AV) e sob duas perspectivas gestuais distintas - procurando observar os graus de influência dos gestos proferidos pelo percussionista, averiguando até que ponto os mesmos podem afetar as sensações de seguimento de um conteúdo musical sobre uma performance em percussão. Ao determinarmos a influência do gesto na percepção de certos conteúdos musicais na música para percussão, poderemos desenvolver conceitos e diretrizes acerca da incorporação e utilização dos gestos em uma performance percussiva.

A obra escolhida para o experimento foi Exil: Shangai 45 (1991), do compositor canadense Michel Longtin (1946 -). Com duração de 23 minutos, a composição é escrita para percussão múltipla solo onde a voz também é utilizada através da recitação de textos em chinês. A razão por eleger este tipo de repertório justificase pela obra ser uma montagem de percussão múltipla (incluindo apenas instrumentos de altura indeterminada), distanciando-se de sonoridades familiares ao ouvinte como harmonias tradicionais, recursos melódicos (de altura definida), de contraponto e sistemas tonais e/ou modais. A ideia será evitar que o indivíduo procure relações desse calibre para apontar as suas percepções de frase, trecho 
ou texto musical. As sonoridades não convencionais poderão mesmo ampliar a percepção de variados pontos culminantes nas frases musicais executadas. Outro motivo para a escolha dessa obra é o fato de a mesma ser pouco veiculada e, como consequência, desconhecida pelo público alvo do experimento. $O$ trecho corresponde à seção $E$ da obra, entre os compassos 96-135, assim divididos: c.96-110 (Ex.4); c.110-123 (Ex.5) e c.123-135 (Ex.6):

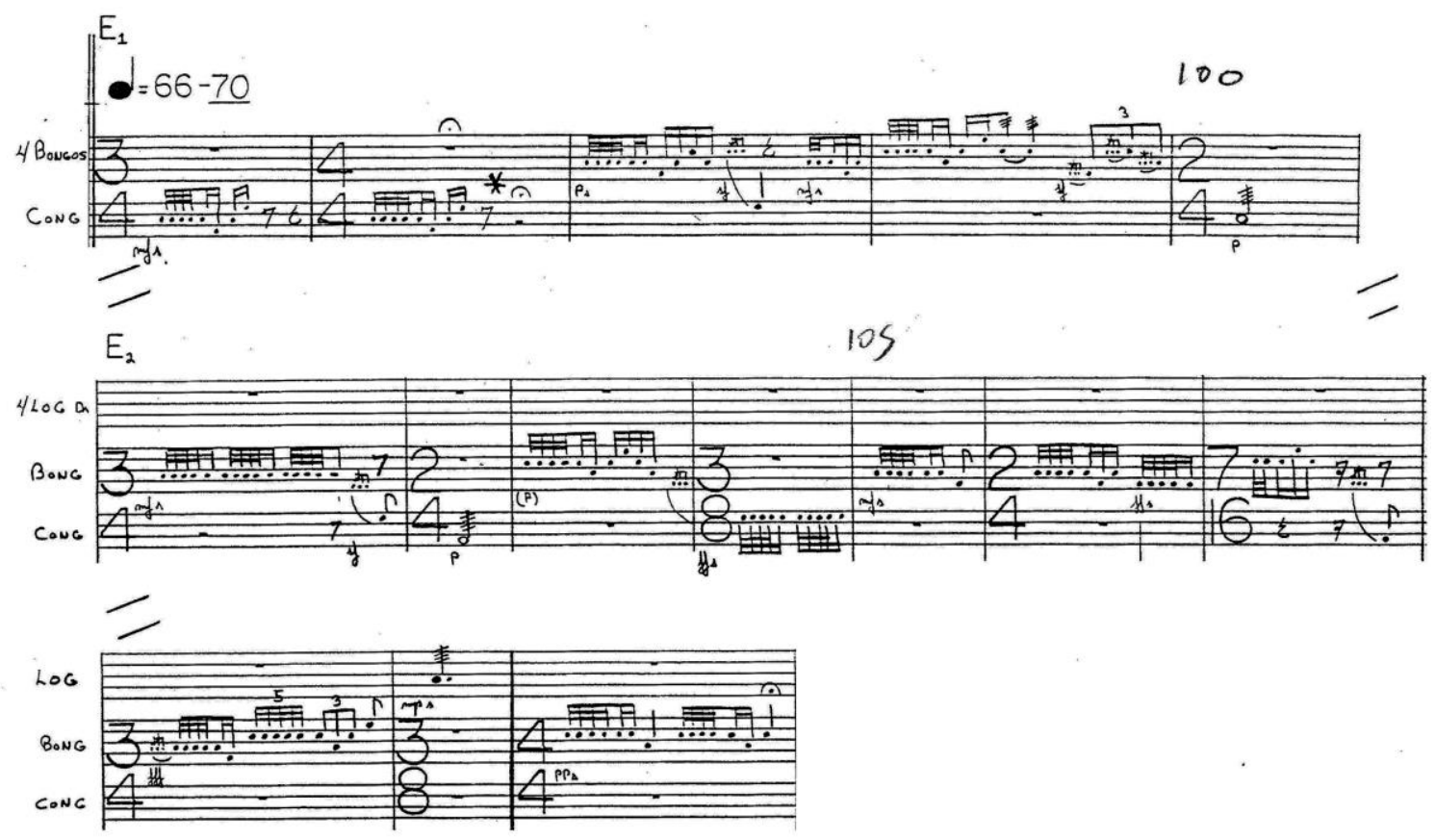

Ex.4 - Exil: Shangai 45 (LONGTIN,1991). c.96-110.
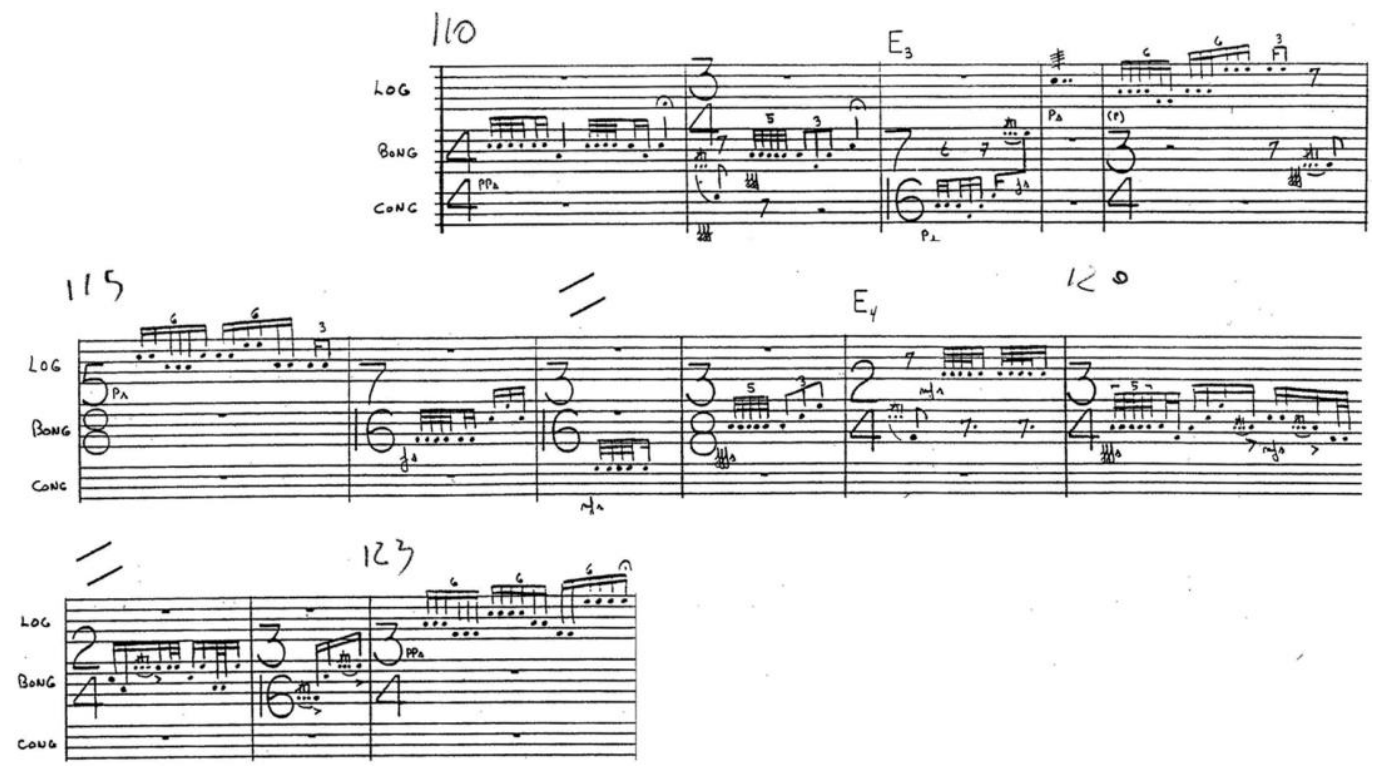

Ex.5 - Exil: Shangai 45 (LONGTIN, 1991). c.110-123. 

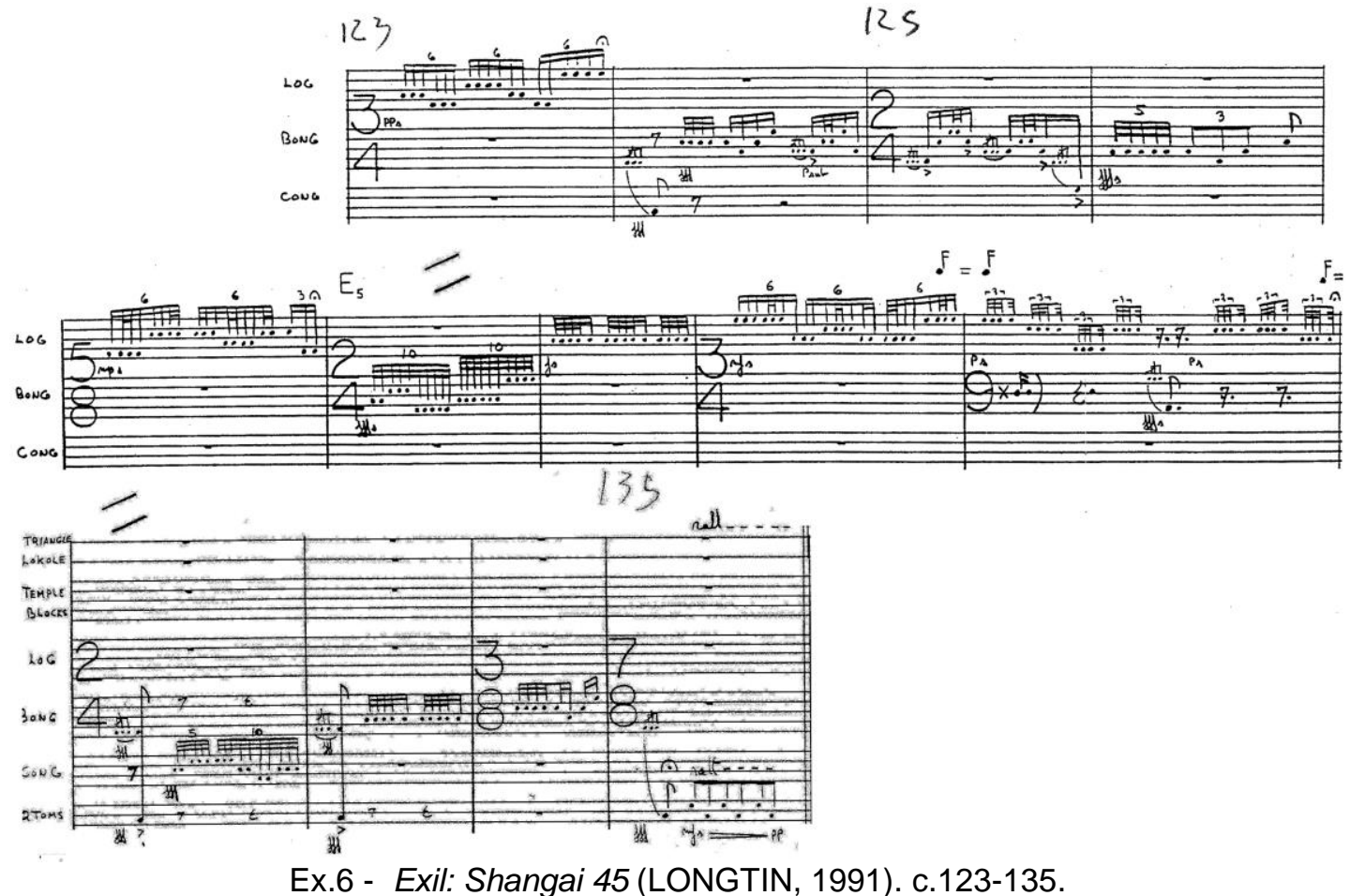

Os três excertos foram gravados sob duas perspectivas gestuais distintas:

- Gesto expressivo (GE) - procura demonstrar uma performance de um músico em concerto, sem inibição dos movimentos corporais após as intervenções sonoras (sejam elas longas ou curtas).

- Gesto técnico (GT) - trata-se do gesto isento de intencionalidade expressiva, procurando exercer os movimentos mínimos necessários para a extração sonora dos instrumentos.

Os gestos GE e GT, por sua vez, foram gravados sob três tipos de estímulos sensoriais: visual (V), auditivo (A) e audiovisual (AV). Ao proporcionarmos três excertos distintos para cada estímulo gravado conseguimos garantir a equidade das informações e textos musicais transmitidos a todos os indivíduos participantes do experimento. Essa divisão feita aos excertos permitiu-nos proporcionar aos participantes do experimento as condições necessárias para a atribuição de suas respostas sem viés. Por se tratarem de três estímulos distintos ( $\mathbf{A}, \mathbf{V}$ e $\mathbf{A V})$ observados, a utilização de apenas um ou dois excertos forçaria a apreciação de um mesmo excerto com estímulos diferentes, o que poderia alterar e/ou induzir a percepção do indivíduo sobre o trecho musical. Como forma de definirmos a avaliação das respostas dos participantes sobre o experimento "Sensação de continuidade de um trecho musical", definimos três graus de sensações possíveis a serem captadas pelo espectador durante a transmissão do experimento, são elas:

- Continuidade - percepção de fluência, sem interrupção ou hesitação do trecho musical executado. 
- Suspensão - percepção de hesitação, interrupção (não conclusiva), percepção inconclusa e não contínua do trecho musical executado.

- Conclusão - percepção de termo do trecho musical executado.

\section{4.a) Transmissão dos Estímulos - Funcionamento do PATCH e} Experimento Teste - Para a realização do experimento "Sensação de continuidade de um trecho musical" utilizamos o software Max/MSP 6.0, desenvolvido para pesquisas sobre linguagem visual em música e multimédia. Através de uma interface (PATCH) gerada por este software os participantes foram convidados a exprimir a sua sensação de continuidade de um trecho musical. Há de se destacar que os indivíduos utilizaram computadores e auriculares de mesma marca e modelo, garantindo a mesma qualidade de exibição dos estímulos entre todos os participantes. A partir dos três excertos da obra Exil: Shangai 45 (LONGTIN, 1991), foram geradas gravações contendo estímulos $\mathbf{A}, \mathbf{V}$ e $\mathbf{A V}$. Os mesmos foram apresentados aos participantes do experimento através do PATCH.

Foi determinado que os participantes escolhidos deveriam possuir considerável conhecimento musical, uma vez que esse tipo de público foca a sua atenção de maneira diferente do público leigo no que diz respeito às informações sonoras passadas durante uma performance. Acreditamos que o receptor com saber musical tem maior probabilidade em não distrair sua atenção do conteúdo musical em função dos gestos realizados pelo performer. Ou seja, caso sejam influenciadas pelos gestos, as suas respostas sobre os estímulos terão credibilidade suficiente paras as conclusões tomadas nas análises realizadas.

Também nos preocupamos em obter respostas de participantes que compreendessem as ideias e/ou conceitos de continuidade, suspensão e conclusão em música de forma equivalente ou, pelo menos, congruente. Assim, procuramos limitar o universo de indivíduos para um experimento que já se apresenta bastante subjetivo. Para não deixarmos margem para dúvida selecionamos músicos com grau superior completo, pois consideramos este nível de formação musical suficiente para realizarem completamente o experimento com sucesso. Foi também determinado que esses indivíduos não poderiam ter relação direta no aspecto performativo e/ou composicional com a percussão, a fim de não obtermos respostas induzidas ou premeditadas por sujeitos que circundam este campo de pesquisa. Desta forma, percussionistas e compositores foram excluídos como parte do público alvo desse experimento.

Para a obtenção das respostas dos participantes acerca das sensações expressas durante a apresentação dos estímulos, utilizamos uma régua temporal (com medida em segundos) na interface apresentada, articulada às teclas dos computadores utilizados. Associamos as cores verde, amarelo e vermelho às teclas 3,6 e 9 respectivamente. Ativado o experimento, ao premir as teclas, as cores referentes apareciam na régua. Esta possui a indicação do tempo do vídeo em segundos no momento da ativação das cores. Destacamos a possibilidade de poder-se acompanhar 0 tempo do estímulo apresentado através de um cronômetro em ms, ativado ao mesmo tempo em que a interface é acionada. 
Desta forma, ao realizarmos uma análise da partitura, conseguimos determinar em que trecho da obra as respostas foram ativadas, gerando assim a base de dados para as averiguações que serão feitas. As cores caracterizaram uma escala subjetiva com três valores gradativos onde a ideia de continuidade convertia-se progressivamente à ideia de conclusão. $O$ verde representou a sensação de continuidade, a cor amarela significou suspensão. A sensação de conclusão de frase foi representada pela cor vermelha.

4.b) Familiarização com o $P A T C H$ - Ao pretendermos receber as primeiras sensações dos participantes relativamente aos estímulos exibidos, não poderíamos correr o risco de criarmos uma situação de tensão e/ou pressão emocional. Isso poderia causar uma indução ao erro uma vez que os mesmos estiveram sendo interrogados sobre algo subjetivo, utilizando uma ferramenta relativamente desconhecida. Assim, foi decidido exibir um vídeo explicativo e um estímulo teste (não vinculados aos estímulos para a captação das respostas, preservando a espontaneidade das mesmas) permitindo uma pré-utilização do programa pelos participantes exatamente como decorrerá no experimento. As gravações contidas trataram-se de dois trechos distintos da obra Phènix (BERNARD-MÂCHE, 1982), Ex.7.

Também distinguimos o estímulos entre o vídeo explicativo do estímulo teste, preservando assim a captura de informações relativas às primeiras sensações do participante perante a exibição do estímulos. A utilização do vídeo explicativo também se justificou pelo fato de todos os participantes, sem exclusão, receberem o mesmo tipo de ferramentas para a compreensão e realização do experimento. Assim, ao receberam tratamento uniforme, pudemos afirmar que não houve margem para favorecimentos ou prejuízos nas respostas assinaladas.

4.c) Coleta de Dados e visualização das respostas - A coleta de dados foi feita perante a exibição dos três tipos de estímulos (A, V e AV). Combinados com os três excertos da obra Exil: Shangai 45 (LONGTIN, 1991), obtivemos dezoito possibilidades distintas de exibições dos estímulos, como podemos observar na Tabela de Diferenciação de Estímulos (Ex.8): 


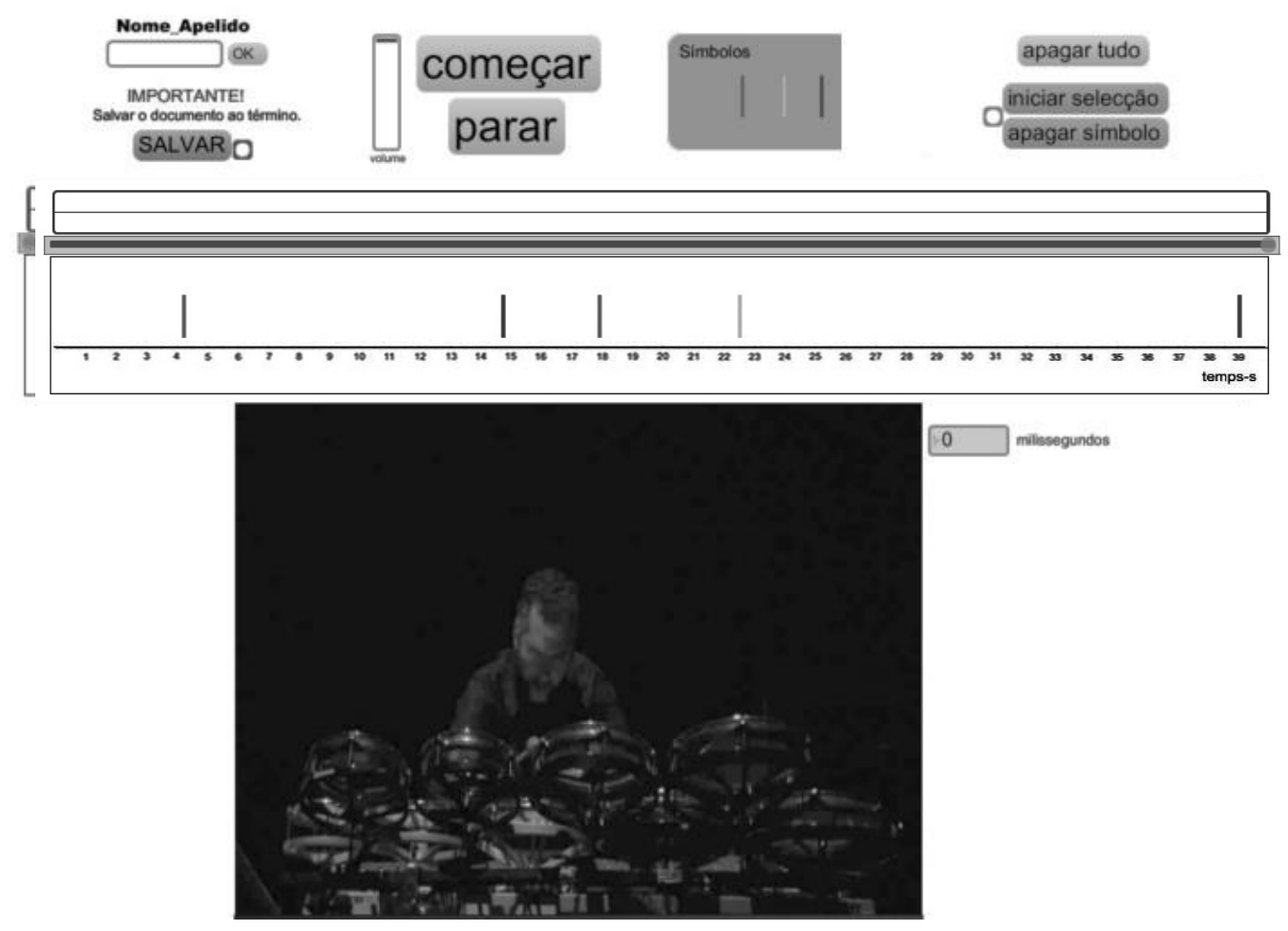

Ex.7 - Imagem do PATCH com o estímulo teste.

\begin{tabular}{|c|c|c|c|}
\hline Atitude dos Gestos & Áudio (A) & Vídeo (V) & Audiovisual (AV) \\
\hline Gesto Expressivo - GE (e) & A1e, A2e, A3e & V1e, V2e, V3e & AV1e, AV2e, AV3e \\
\hline Gesto Técnico - GT (t) & A1t, A2t, A3t & V1t, V2t, V3t & AV1t, AV2t, AV3t \\
\hline
\end{tabular}

Ex.8 - Tabela de Diferenciação de Estímulos, onde: At (áudio técnico), Ae (áudio expressivo), Vt (vídeo técnico), Ve (Vídeo expressivo), AVt (audiovisual técnico), AVe (audiovisual expressivo).

A interface foi apresentada a um conjunto de seis indivíduos (In.) divididos em três grupos (Gr.) contendo dois participantes em cada grupo. Desta forma, obtemos ao todo 36 respostas para serem analisadas (Ex.9):

\begin{tabular}{lll}
\hline In.1 e In.2 & $\begin{array}{l}\text { In.1 e In.2 } \\
\text { Gr. I }\end{array}$ & $\begin{array}{l}\text { In.1 e In.2 II } \\
\text { Gr. III }\end{array}$ \\
\hline A1t & A2t & A3t \\
A3e & A1e & A2e \\
V2t & V3t & V1t \\
V1e & V2e & V3e \\
AV3t & AV1t & AV2t \\
AV2e & AV3e & AV1e \\
\hline
\end{tabular}

Ex.9 - Divisão dos Estímulos por grupos, onde: In. (Indivíduo), Gr. (grupo).

Por estarmos cientes de que a régua temporal presente no PATCH serviria, em primeiro plano, como um apoio ao participante para seguir visualmente as suas respostas no experimento, desenvolvemos na interface outra função que nos permitisse obter os dados coletados no formato plain text (.txt), sob duas medidas de tempo possíveis. A primeira medida de tempo diz respeito à medição feita pelo 
próprio programa no formato Quick Time, podendo ser descartada ${ }^{10}$ nas análises. A segunda medida (a que nos interessa) foi a presentada em milésimos de segundo (mstime). Foram fornecidos no texto dois timings, que correspondem um ao tempo de ativação e outro ao aparecimento da cor na régua. Estas medidas apresentaram de forma milimétrica a ativação das cores no momento em que os estímulos foram apresentados, resguardando o tempo exato de ativação das respostas. No momento em que o experimento era salvo pelo participante, as respostas eram apresentadas em uma pasta de arquivo no computador, no formato .txt, sem haver qualquer prejuízo de imagem ou som no decorrer da experiência. $O$ formato .txt não reconhece os números das teclas do computador de acordo com as cores ativadas, mas as relaciona em ordem alfabética: $a=$ verde, $b=$ amarela, $d=$ vermelha (Ex.10 e Ex.11) $)^{11}$ :

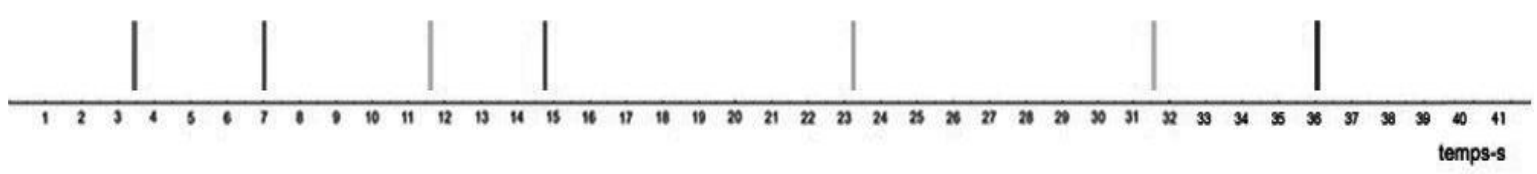

Ex.10 - Régua em segundos, In.1 - Gr.I - A3e.

a 78 mstime 3275
a 163 mstime 6833
b 272 mstime 11394
a 347 mstime 14530
b 549 mstime 22957
b 746 mstime 31170
d 853 mstime 35659

Ex.11 - Resposta em formato plain text (.txt) em Quick Time e mstime. In.1 - Gr.I - A3e.

Todos os estímulos foram exibidos duas vezes do início ao fim. A primeira exibição, sem interrupção, serviu para a recolha dos dados. A diferença de velocidade de resposta do participante entre o momento da sua sensação e a ativação da tecla do computador poderia existir e gerar um pequeno atraso no recebimento das informações pela interface. Mesmo em se tratando de um atraso mínimo que não acusou relevância para os resultados, percebemos que o tempo de resposta poderia variar ao menos 0,5 segundos para mais ou para menos. Este foi um dos motivos pelo qual definiu-se que a segunda exibição serviria para uma eventual revisão ou correção de erros sobre as respostas. Considerando as condições que poderiam afetar o imediatismo das respostas (como por exemplo a relação de velocidade entre a observação da interface e o premir da tecla do computador), admitimos uma tolerância de tempo entre de 0,1s e 0,5s, para mais ou para menos, relativamente à cor acionada. Cada caso foi observado e estudado para não haver o risco de excluir respostas sobre tempos e regiões relevantes. Assim, arredondamos as respostas em centésimos de segundo para melhor serem enquadradas na matriz de dados e para obtermos uma visualização das médias com maior clareza. O arredondamento foi possível já que as medidas de tempo em centésimos e milésimos de segundo não alteraram a observação das regiões onde as cores foram acionadas. Por exemplo, a diferença entre 
3,872s e 4s não alterou a nossa percepção da região do trecho musical executado relativamente às respostas ocorridas.

4.d) Análise dos dados - A análise do experimento está dividida em duas partes. A primeira tratou-se de uma Análise Percentual dos Dados (APD), permitindo criar relações entre as respostas especificas sobre os trechos utilizados no experimento. A segunda parte da análise utilizou a técnica estatística de Análise Fatorial de Correspondências (AFC). Neste artigo, nos ateremos aos resultados obtidos através da APD. Para construirmos a tabela de contingência (matriz) utilizada na APD, decidimos seccionar os excertos exibidos por zonas. Procuramos os momentos nos excertos que ilustram situações que acreditamos "desestabilizar" um sentido de continuidade (por exemplo, situações de "ruptura", "quebra", "tensão", etc.) ${ }^{12}$. A essas circunstâncias denominamos Fatores Contextuais $(\mathrm{F})$.

Baseamos os Fatores Contextuais (F) no princípio de regras oriundas da teoria da Gestalt. Apesar de esta teoria da psicologia moderna estar atrelada originalmente aos fenômenos visuais (uma vez que refere-se a um processo de dar forma, de configurar o que é colocado diante dos olhos), foi possível estabelecer um paralelo com a teoria musical. A abordagem que a Escola "Dualista" de Graz faz a respeito da identificação dos processos de percepção sensorial auxiliou-nos a perceber a relação que buscamos. Os dualistas defendem a distinção de dois momentos da "elaboração" da forma daquilo que observamos: a sensorial proveniente apenas do objeto observado; a mental (perceptiva) - resultante do trabalho intelectual ao qual se dá um sentido à forma. O primeiro diz respeito à sensação que será função apenas de uma variável (condições externas), remetendo à percepção pura dos elementos que compõe uma configuração qualquer (por exemplo o formato puro de uma imagem ou, numa perspectiva sonora, as notas musicais). O segundo aborda a percepção como função de duas variáveis (condições externas e internas). Ou seja, o agrupamento desses elementos, ao estimular os processos de percepção (exercício intelectual), adquirem um sentido (por exemplo a forma visual de um objeto ou os sons captados pelo ouvido transformados em melodia ou harmonia).

Nos estudos de YOST (2000) observamos um domínio sobre essas teorias, o que Ihe permitiu classificar os índices físicos que o sistema auditivo tem em conta para uma análise dos eventos sonoros captados auditivamente. Aliando as regras de proximidade e de mudança de LERDHAL e JACKENDO (1983), pensamos que será determinante, para o nosso trabalho, canalizarmos as atenções para os seguintes pontos descritos por YOST (2000): separação/perfil espectral e amplitude de frequência (timbre); modulações de amplitude (dinâmica, volume); separação temporal (ritmo, tempo); sincronização dos ataques e silêncios (momento do toque e momento após o toque). Percebemos a existência de uma proximidade entre os conceitos analisados pelos diferentes autores e que, não por acaso, os Fatores Contextuais estão atrelados aos parâmetros do som. Essas características sonoras e musicais encontradas nos excertos analisados foram fundamentais para a determinação dos mesmos. A seguir, demonstramos os Fatores Contextuais utilizados no processo de análise das respostas dos indivíduos participantes do experimento (Ex.12): 
Por se tratarem dos eventos sonoros com características alheias aos fatores $\mathrm{F} 1 \mathrm{a}$ F7, o fator F8 caracterizou-se exatamente por agregar momentos que não contém situações de "ruptura", "quebra", "tensão", "suspensão", etc. Em Ex.13, por exemplo, F8 surgiu pela primeira vez de forma oculta no Excerto $1 t$ entre 4,2s e 5,1s. Baseando-nos nesses oito Fatores Contextuais e, ao realizarmos uma análise interpretativa da partitura, dividimos os excertos em pequenas zonas. Ao seccionarmos os excertos, tornou-se mais clarividente e fácil de analisar as situações análogas ou antagônicas das respostas obtidas no experimento (Ex.13, Ex.14 e Ex.15).

\begin{tabular}{|c|c|}
\hline $\begin{array}{c}\text { FATOR } \\
\text { CONTEXTUAL }\end{array}$ & SIGNIFICADO \\
\hline $\mathbf{F 1}$ & Ausência de intervenção sonora do intérprete \\
\hline F2 & Mudança brusca de timbre \\
\hline F3 & Mudança brusca de dinâmica \\
\hline F4 & Mudança brusca de timbre + mudança brusca de dinâmica \\
\hline F5 & $\begin{array}{l}\text { Mudança brusca de dinâmica + } \\
\text { duração de execução da nota tocada (rulo) }\end{array}$ \\
\hline F6 & $\begin{array}{l}\text { Mudança brusca de timbre + mudança brusca de dinâmica } \\
\text { + duração de execução da nota tocada }\end{array}$ \\
\hline F7 & $\begin{array}{l}\text { Mudança brusca de timbre + } \\
\text { Ausência de intervenção sonora do intérprete }\end{array}$ \\
\hline F8 & $\begin{array}{l}\text { Demais situações geradas, alheias aos demais fatores, } \\
\text { que vem significar momentos de continuidade do trecho }\end{array}$ \\
\hline
\end{tabular}

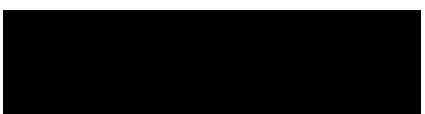

\section{EXCERTO 1t 10 som à $4,2 \mathrm{~s}$}

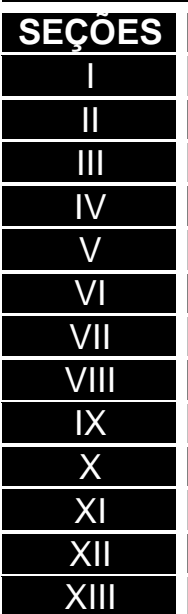

De (em s) à (em s)

\begin{tabular}{|c|}
\hline COMPASSO \\
\hline 96 \\
97 \\
98
\end{tabular}

5,2
8,6

7,5

12,6

11

15,5

13,5

$15,5 \quad 16,5$

\begin{tabular}{l|l}
17,5 & 20,7 \\
\hline
\end{tabular}

\begin{tabular}{l|l}
17,5 & 20,7 \\
\hline 21,8 & 23,6 \\
\hline
\end{tabular}

\begin{tabular}{c|c}
\hline 25 & 25,4 \\
\hline 26,4 & 26,6 \\
\hline
\end{tabular}

\begin{tabular}{l|l}
28,4 & 28,6 \\
\hline
\end{tabular}

1,5

De (em s) EXCERTO 1e
10 som a $0,3 \mathrm{~s}$

1,2

à (em s)

3,8

3,8

2,8

2,8
5,7

FATOR (F)

9,7

7,3
9,7

7,8

11,4

$\frac{10,5}{13}$

15,2

13

\begin{tabular}{l|l}
18,4 & 18,7 \\
\hline
\end{tabular}

19,6

\begin{tabular}{r|r}
19,6 & 19,8 \\
\hline 21,7 & 22 \\
\hline 23,5 & 24 \\
\hline
\end{tabular}

18,7

\begin{tabular}{|l|l|}
\hline 17,7 & 4 \\
\hline 9,8 & 4 \\
\hline 22 & 3 \\
\hline 24 & 1 \\
\hline
\end{tabular}

\begin{tabular}{|l|c|c|c|c|c|}
\hline 107 & 30,5 & 31 & 23,5 & 24 & 1 \\
\hline 109 & 33 & 36 & 26,5 & 29 & 6 \\
\hline 110 & 37,1 & 37,9 & 29,3 & 30 & 2 \\
\hline 110 & 39 & 42 & 30,8 & 35,3 & 1 \\
\hline
\end{tabular}

Ex.13 - Seções por Fator Contextual (F) do Ex.4. 


\begin{tabular}{|c|c|c|c|c|c|c|}
\hline & & $\begin{array}{l}\text { EXCER } \\
1^{\circ} \text { som }\end{array}$ & $\begin{array}{l}02 \mathrm{~T} \\
0,8 \mathrm{~s}\end{array}$ & $\begin{array}{l}\text { EXCER } \\
1^{\circ} \text { som }\end{array}$ & $\begin{array}{l}02 \mathrm{E} \\
1,2 \mathrm{~s}\end{array}$ & \\
\hline SEÇOES & COMPASSO & $\mathrm{De}(\mathrm{em} \mathrm{s})$ & à (em s) & $\mathrm{De}(\mathrm{em} \mathrm{s})$ & à $(\mathrm{em} \mathrm{s})$ & FATOR (F) \\
\hline 1 & 110 & 1,7 & 2,3 & 2,2 & 2,8 & 1 \\
\hline II & 110 & 3,4 & 4,5 & 3,8 & 5,7 & 1 \\
\hline III & 111 & 4,7 & 6,7 & 5,8 & 7,4 & 5 \\
\hline$\overline{\text { IV }}$ & 111 & 6,7 & 9,3 & 7,5 & 8,0 & 1 \\
\hline $\mathrm{V}$ & 112 & 10.2 & 10,5 & 9,2 & 9,4 & 5 \\
\hline $\mathrm{VI}$ & 113 & 10,6 & 12,0 & 9,5 & 10,4 & 8 \\
\hline$\overline{\mathrm{VII}}$ & 114 & 13,9 & 14,4 & 12,7 & 13,0 & 5 \\
\hline VIII & 115 & 14,6 & 16,5 & 13,2 & 15,1 & 5 \\
\hline IX & 116 & 16,6 & 20,2 & 15,5 & 18,6 & 5 \\
\hline $\bar{X}$ & 119 & 20,3 & 21,4 & 18,8 & 20,3 & 5 \\
\hline$\overline{X I}$ & 120 & 21,5 & 26,2 & 20,4 & 25,1 & 5 \\
\hline$\overline{X I I}$ & 123 & 26,3 & 28,7 & 25,2 & 27,8 & 5 \\
\hline XIII & 123 & 28,8 & 32,5 & 27,9 & 31,4 & 1 \\
\hline
\end{tabular}

Ex.14 - Seções por Fator Contextual (F) do Ex.5.

\begin{tabular}{|c|c|c|c|c|c|c|}
\hline & & $\begin{array}{l}\text { EXCEF } \\
1^{\circ} \mathrm{som}\end{array}$ & $\begin{array}{l}0 \text { 3T } \\
0,7 \mathrm{~s}\end{array}$ & $\begin{array}{l}\text { EXCER } \\
1^{\circ} \text { som }\end{array}$ & $\begin{array}{l}\text { TO 3E } \\
0,8 \mathrm{~s}\end{array}$ & \\
\hline SEÇOES & COMPASSO & $\mathrm{De}(\mathrm{em} \mathrm{s})$ & à (em s) & $\mathrm{De}(\mathrm{em} \mathrm{s})$ & à (em s) & FATOR (F) \\
\hline 1 & 123 & 3,3 & 4,0 & 3,4 & 4,6 & 1 \\
\hline II & 124 & 4,2 & 4,6 & 4,8 & 5,0 & 4 \\
\hline III & 124 & 4,7 & 5,7 & 5,1 & 6,2 & 2 \\
\hline IV & 124 & 5,8 & 8,0 & 6,3 & 8,5 & 3 \\
\hline $\mathrm{V}$ & 125 & 8,2 & 8,4 & 8,6 & 8,7 & 4 \\
\hline$\overline{\mathrm{VI}}$ & 126 & 8,5 & 10,0 & 8,8 & 10,2 & 4 \\
\hline VII & 126 & 9,9 & 10,2 & 10,3 & 10,6 & 1 \\
\hline VIII & 127 & 10,3 & 12,8 & 10,7 & 13,1 & 4 \\
\hline IX & 127 & 12,9 & 13,6 & 13,2 & 14,1 & 1 \\
\hline $\bar{X}$ & 128 & 13,7 & 15,7 & 14,2 & 16,1 & 4 \\
\hline$\overline{X I}$ & 129 & 15,8 & 17,3 & 16,2 & 17,3 & 3 \\
\hline XII & 131 & 21,7 & 22,2 & 22,2 & 22,6 & 4 \\
\hline XIII & 131 & 22,3 & 23,6 & 22,7 & 23,8 & 4 \\
\hline XIV & 132 & 23,8 & 24,2 & 24,0 & 24,5 & 7 \\
\hline $\mathrm{XV}$ & 132 & 24,3 & 26,2 & 24,6 & 26,2 & 3 \\
\hline$\overline{X V I}$ & 133 & 26,3 & 26,7 & 26,3 & 26,9 & 7 \\
\hline$\overline{X V I I}$ & 133 & 26,8 & 29,2 & 27,0 & 29,6 & 3 \\
\hline XVIII & 135 & 29,4 & 30,4 & 29,8 & 31,6 & 7 \\
\hline XIX & 135 & 30,5 & 36,6 & 31,7 & 38,2 & 3 \\
\hline$X X$ & 135 & 36,7 & 39,2 & 38,3 & 41,8 & 1 \\
\hline
\end{tabular}

Ex.15 - Seções por Fator Contextual (F) do Ex.6.

5. Análise Percentual dos Dados (APD) - O intuito desta análise foi o de observarmos as relações nas tabelas que se seguirão, em termos percentuais, entre as linhas (onde estão os estímulos), entre colunas (onde estão as sensações) e entre linhas e colunas. Ressalta-se que esse tipo de análise limitou- 
se aos resultados deste experimento em particular, sendo esta uma forma de ilustrá-los. Na matriz utilizada para a APD (Ex.16) podemos visualizar em cada linha os estímulos A, V e AV, para execução técnica $(\mathbf{t})$ - ou gesto técnico GT- ou execução expressiva (e) - gesto expressivo GE que geraram 36 respostas. Nas colunas podemos ver os Fatores Contextuais F1 a F8, e as respectivas sensações de continuidade (a) , suspensão (b) e de conclusão (d). Cada elemento da tabela é o número de respostas dadas para cada sensação, segundo cada estímulo.

Considerando os Fatores Contextuais, as zonas de ocorrência nos excertos e as respostas dos participantes no experimento "Sensação de continuidade de um trecho musical", elaboramos uma Matriz (tabela de contingência) para a APD (Ex.16). Baseados nos dados dessa tabela (matriz com os resultados obtidos das respostas dadas para cada estímulo), elaboramos um conjunto de tabelas (Ex.17, Ex.18, Ex.19, Ex.20, Ex.21, Ex.22, Ex.23 e Ex.24) onde foram computadas as diversas percentagens que nos ajudaram a compreender tais resultados.

A tabela Ex.17 indica-nos nas linhas a representação dos estímulos, e nas colunas os fatores (F) subdivididos pelas sensações de continuidade (verde), suspensão (amarela) e conclusão (vermelha). O total global vem significar a soma de todas as respostas, independentemente do estímulo (soma-se, por tanto, as respostas atribuídas em $\mathbf{A}, \mathbf{V}$ e $\mathbf{A V}$ ). Já em Ex.18 visualizamos nas linhas os estímulos e nas colunas os fatores $(F)$ subdivididos pelas sensações de continuidade (verde), suspensão (amarela) e conclusão (vermelha). Nessa tabela ilustramos os valores percentuais sobre o total de cada estímulo, por sensação e em cada fator.

Para percebermos Ex.19 deveremos observar nas linhas a representação do total dos estímulos $\mathbf{A e}+\mathbf{V e}+\mathbf{A V e}$ para o gesto expressivo (GE) e $\mathbf{A t}+\mathbf{V t}+\mathbf{A V t}$ para o gesto técnico (GT). Nas colunas estão representados os fatores (F) subdivididos pelas sensações de continuidade (verde), suspensão (amarela) e conclusão (vermelha). Essa tabela demonstra os valores percentuais por fator $(\mathrm{F})$ e sensação, na soma de todos os estímulos em GE e GT.

Ex.20 ilustra nas linhas cada estímulo (A, V e AV) agregado a cada gesto (GE e GT). Nas colunas observamos os fatores (F). Apresenta-se, nessa tabela, os valores percentuais por fator $(F)$, sobre o total de cada estímulo em GE e GT. Será dizer que, do total atribuído no experimento a Ve, por exemplo, 34\% das marcações desse estímulo correspondem a F8.

A construção de Ex.21 mostra-nos, nas linhas, cada estímulo ( $\mathbf{A}, \mathbf{V}$ e $\mathbf{A V}$ ) agregado a cada gesto (GE e GT) sendo que, nas colunas, observamos os fatores (F) subdivididos pelas sensações de continuidade (verde), suspensão (amarela) e conclusão (vermelha). Essa tabela nos indica os valores percentuais totais em cada fator (F), por sensação, para cada estímulo em GE e GT.

As tabelas Ex.22, Ex.23 e Ex.24 ilustram, nas linhas, as somas de estímulos (A/V, A/AV ou V/AV) aliados ao GE e GT e, nas colunas, os fatores (F1, F3, F4, F6 e 
F8) subdivididos pelas sensações de continuidade (verde), suspensão (amarela) e conclusão (vermelha). Essas tabelas indicam os valores percentuais na soma dos estímulos em GE e GT, sobre o total da sensação.

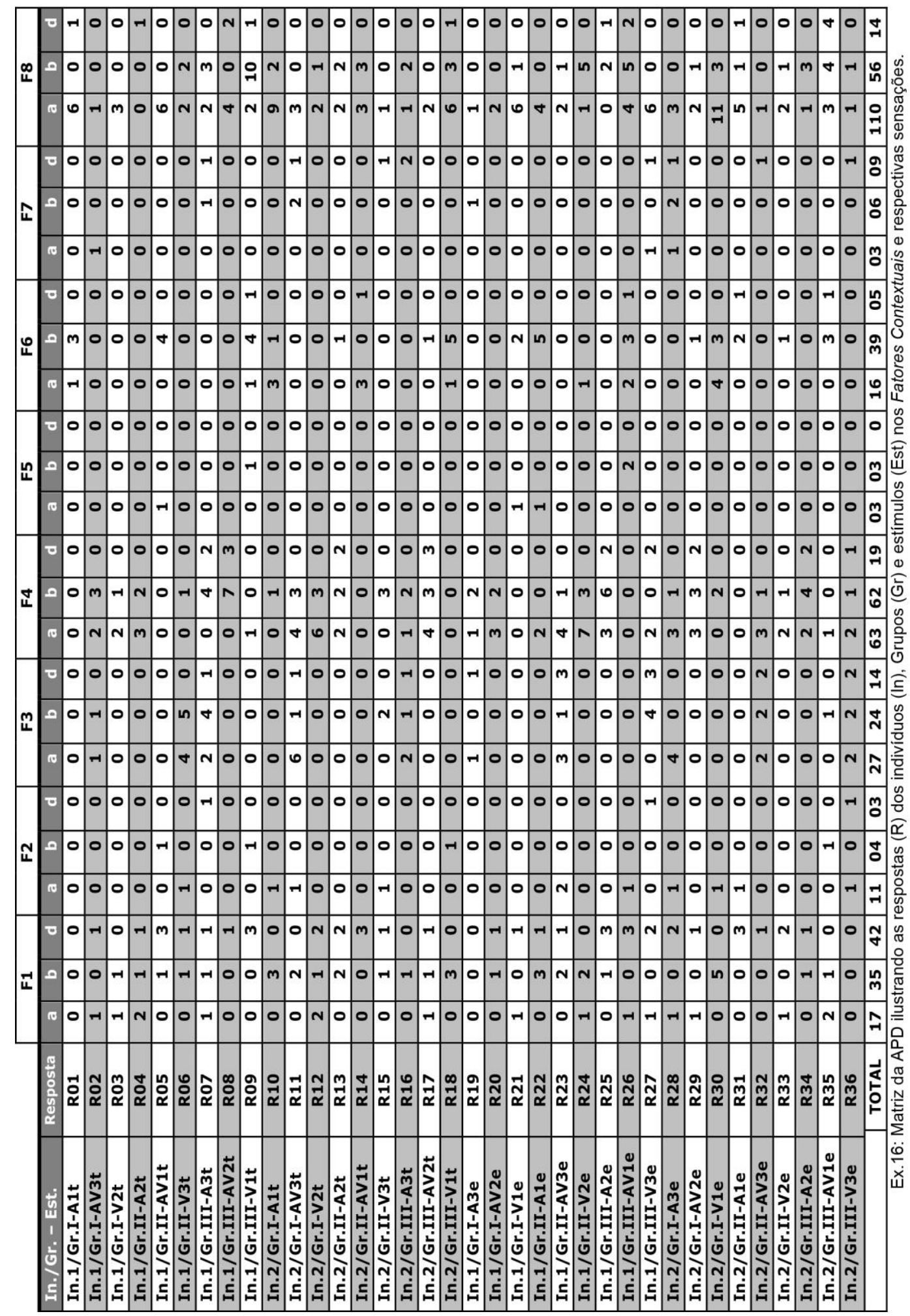




\begin{tabular}{|c|c|c|c|c|}
\hline \multirow{3}{*}{$\underset{\leftarrow}{\infty}$} & $\stackrel{\infty}{\sim}$ & 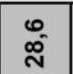 & $\stackrel{m}{\underset{f}{*}}$ & $\bar{i}$ \\
\hline & $=\bar{m}$ & \begin{tabular}{|l|} 
\\
$\stackrel{\infty}{0}$ \\
$\stackrel{0}{0}$
\end{tabular} & $\underset{\substack{n \\
\mathfrak{g}}}{\mathfrak{w}}$ & $\stackrel{\mathscr{N}}{ }$ \\
\hline & $\overline{\overline{0}}$ & 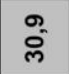 & $\overline{8}$ & 品 \\
\hline o & 吕 & 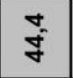 & m. & $\tilde{\text { กี }}$ \\
\hline 느응 & $\begin{array}{c}m \\
m \\
m\end{array}$ & $\hat{\emptyset}$ & 0 & ల్ల \\
\hline & $\hat{\varphi}$ & $\stackrel{m}{p}$ & m & ల్లె \\
\hline - & ${ }_{\infty}^{m}$ & ก & $\stackrel{\sim}{\circ}$ & 8 \\
\hline 니은 & $\mathscr{c}$ & 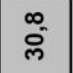 & $\begin{array}{l}\infty \\
\substack{\infty \\
\infty}\end{array}$ & $\stackrel{\infty}{\circ}$ \\
\hline$\sigma$ & $\mid \begin{array}{c}\hat{\sim} \\
\dot{s}\end{array}$ & $\stackrel{\infty}{N}$ & $\hat{\tilde{g}}$ & $\frac{N}{\bar{m}}$ \\
\hline 0 & 0 & $\begin{array}{l}0 \\
\end{array}$ & 0 & $\circ$ \\
\hline เீ. & is & 0 & $\stackrel{m}{m}$ & $\hat{\varnothing}$ \\
\hline . & is & $\stackrel{m}{m}$ & m్లn & ల్లె \\
\hline . & $\stackrel{\tilde{m}}{\sim}$ & $\overline{\tilde{J}}$ & 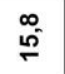 & $\overline{\mathfrak{z}}$ \\
\hline . & $\bar{g}$ & $\hat{\tilde{p}^{\circ}}$ & $\frac{\text { d }}{\mathfrak{n}}$ & $\overline{\tilde{m}}$ \\
\hline \% & $\hat{g}$ & $\hat{N}$ & 孚 & $\bar{\infty}$ \\
\hline 0 & $\frac{\infty}{i=1}$ & $\frac{\pi}{i}$ & $\widehat{\hat{p}}$ & $\stackrel{\mathscr{\vartheta}}{\tilde{y}}$ \\
\hline . & in & \begin{tabular}{|l|}
\multirow{0}{*}{} \\
$\stackrel{0}{ }$
\end{tabular} & 葛 & $\stackrel{2}{2}$ \\
\hline . & $\mid \begin{array}{ll}0 \\
7\end{array}$ & $\begin{array}{c}m \\
\text { m. } \\
\tilde{m}\end{array}$ & $\tilde{\text { กี }}$ & 莳 \\
\hline - & $\hat{o}$ & $\stackrel{m}{m}$ & $\hat{\Xi}$ & 0 \\
\hline ๙ & N & 0 & is & in \\
\hline \% & $=$ & $\stackrel{m}{\sim}$ & $\begin{array}{l}\text { đे } \\
\text { है }\end{array}$ & $\begin{array}{l}\text { ¿े } \\
\text { है }\end{array}$ \\
\hline 0 & $\hat{f}$ & \begin{tabular}{|l|} 
\\
me \\
\end{tabular} & 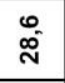 & $\bar{\infty}$ \\
\hline 디. & $=$ & $\overline{\bar{m}}$ & $q$ & มิ \\
\hline${ }^{\circ}$ & $\stackrel{-\bar{\infty}}{\Phi}$ & 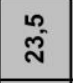 & $\frac{n}{7}$ & 趈 \\
\hline & 웅 & & & 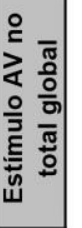 \\
\hline
\end{tabular}

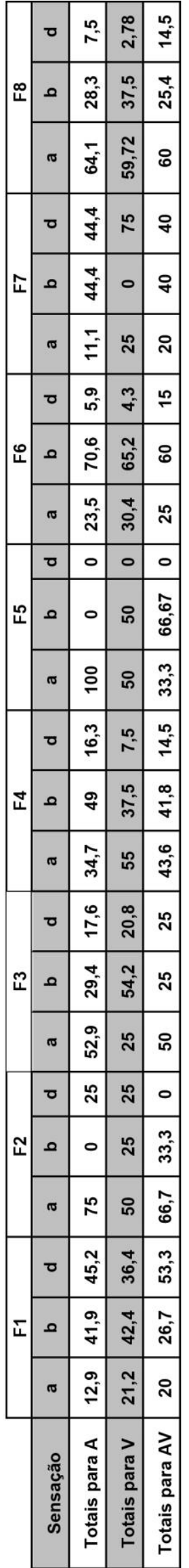

49 


\begin{tabular}{|c|c|c|c|}
\hline & ठ & $\underset{0}{N}$ & $\stackrel{\infty}{\infty}$ \\
\hline \multirow[t]{2}{*}{ జ } & ـ & 畺 & $\begin{array}{l}\stackrel{2}{0} \\
\stackrel{0}{0}\end{array}$ \\
\hline & $\pi$ & $\frac{1}{6}$ & $\begin{array}{l}7 \\
8 \\
8\end{array}$ \\
\hline \multirow{3}{*}{ is } & ठ & 吕 & 足 \\
\hline & م & $\stackrel{m}{m}^{m}$ & ల్ల $^{m}$ \\
\hline & $\pi$ & 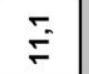 & స̃ \\
\hline \multirow{3}{*}{ 通 } & ठ & $\hat{0}$ & 우 \\
\hline & م & $\mathscr{c}_{0}^{m}$ & \begin{tabular}{l}
$:$ \\
$\notin$ \\
\hdashline
\end{tabular} \\
\hline & $\pi$ & ஓ్ల & 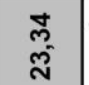 \\
\hline \multirow{3}{*}{ 象 } & ठ & 0 & 0 \\
\hline & - & 요 & 오 \\
\hline & $\pi$ & 요 & 요 \\
\hline \multirow{3}{*}{ 妾 } & ס & $\stackrel{m}{+}$ & 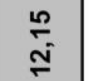 \\
\hline & ـ & is & 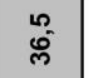 \\
\hline & $\pi$ & 今心 & $\frac{m}{5}$ \\
\hline \multirow{3}{*}{$\tilde{m}$} & ठ & $\stackrel{\Delta}{\sigma}$ & ભ్ల్ల \\
\hline & م & $\hat{\tilde{g}}$ & 今. \\
\hline & \% & $\begin{array}{l}0 \\
\text { of } \\
\text { के }\end{array}$ & ¿্ల \\
\hline \multirow{3}{*}{ พิ } & ס & 0 & กิ \\
\hline & م & $\begin{array}{l}\text { م⿱ } \\
\stackrel{m}{m}\end{array}$ & 웅 \\
\hline & $\sigma$ & $\begin{array}{l}\text { జ̊ } \\
\text { d. }\end{array}$ & $R$ \\
\hline \multirow{4}{*}{$\overline{1}$} & ठ & 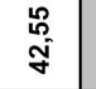 & $\begin{array}{l}\infty \\
\infty \\
\dot{q}\end{array}$ \\
\hline & 2 & $\begin{array}{l}\text { fo } \\
\text { ó }\end{array}$ & స్ల \\
\hline & $\sigma$ & 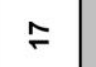 & $\stackrel{\text { }}{\leftarrow}$ \\
\hline & 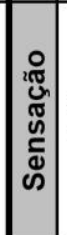 & 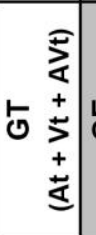 & 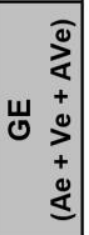 \\
\hline
\end{tabular}

\begin{tabular}{|c|c|c|c|c|c|c|c|}
\hline & ס & 8 & 0 & 0 & $\bullet$ & $\stackrel{9}{-}$ & $\stackrel{\infty}{\circ}$ \\
\hline \multirow[t]{2}{*}{$\stackrel{\infty}{4}$} & مـ & $\hat{N}$ & શి & ని & F & డొల & $\stackrel{m}{=}$ \\
\hline & ల & ষ & ณึ & $\bar{\pi}$ & F & \& & R \\
\hline \multirow{3}{*}{ L } & ס & 오 & $\stackrel{\mathfrak{R}}{\sim}$ & $\widehat{\iota}$ & 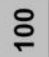 & 응 & $\stackrel{2}{\sim}$ \\
\hline & مـ & ๑ & $\stackrel{\sim}{N}$ & 0 & 0 & 0 & 요 \\
\hline & ర & ㅇ & 0 & ల్ల & 0 & 0 & ผ \\
\hline \multirow{3}{*}{ 눈 } & ర & $\stackrel{m}{\leftarrow}$ & 0 & 0 & $\stackrel{\circ}{\circ}$ & $\stackrel{\infty}{-}$ & $\mp$ \\
\hline & مـ & $\underset{\infty}{\infty}$ & 요 & น & $\stackrel{\mathfrak{R}}{\sim}$ & छ & เి \\
\hline & ( & 0 & J & \& & 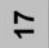 & $\stackrel{\infty}{-}$ & ભ్ల \\
\hline \multirow{3}{*}{ น } & ర & 0 & 0 & 0 & 0 & 0 & 0 \\
\hline & مـ & 0 & 0 & 0 & 0 & 0 & 0 \\
\hline & ర & 0 & 0 & 0 & 0 & 0 & 0 \\
\hline \multirow{3}{*}{ 난 } & ठ & $\underset{\sim}{ }$ & $\stackrel{\circ}{-}$ & $\stackrel{m}{=}$ & 0 & 0 & $\stackrel{9}{\leftarrow}$ \\
\hline & مـ & $\mathscr{q}$ & กิ & ి్లి & F & ి్ల & 요 \\
\hline & ๘ & 尺్ల & ని & in & กี & $\overline{6}$ & $\bar{m}$ \\
\hline \multirow{3}{*}{$\stackrel{m}{4}$} & ס & $\approx$ & $\stackrel{\infty}{\leftarrow}$ & 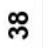 & 0 & $\mathscr{ల}$ & 우 \\
\hline & مـ & 0 & $\stackrel{5}{8}$ & $\mathscr{q}$ & Ð & ని & ి \\
\hline & ๘ & œ & હ्ల & $\stackrel{\sim}{\sim}$ & $\stackrel{ల}{0}$ & ల్ల & ㅇ \\
\hline \multirow{3}{*}{ ్ } & ठ & 0 & 0 & 오 & 0 & 0 & 0 \\
\hline & مـ & 0 & 0 & 0 & ㅇํ & ผ & 오 \\
\hline & ת) & 음 & 음 & 요 & 유 & $\stackrel{2}{\kappa}$ & 으 \\
\hline \multirow{4}{*}{$\bar{\leftarrow}$} & ర & ஜే & N & $\bar{m}$ & $\subsetneq$ & F & ๑ \\
\hline & مـ & $\bar{m}$ & กี & 8 & ఫ & $\hat{N}$ & $\hat{\sim}$ \\
\hline & ర & $\bullet$ & 오 & ผ & $\stackrel{\infty}{\sim}$ & $\hat{N}$ & $\stackrel{m}{\sim}$ \\
\hline & 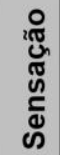 & $\stackrel{0}{<}$ & 艺 & $\stackrel{0}{>}$ & $>$ & 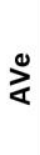 & $\underset{丶}{\gtrless}$ \\
\hline
\end{tabular}



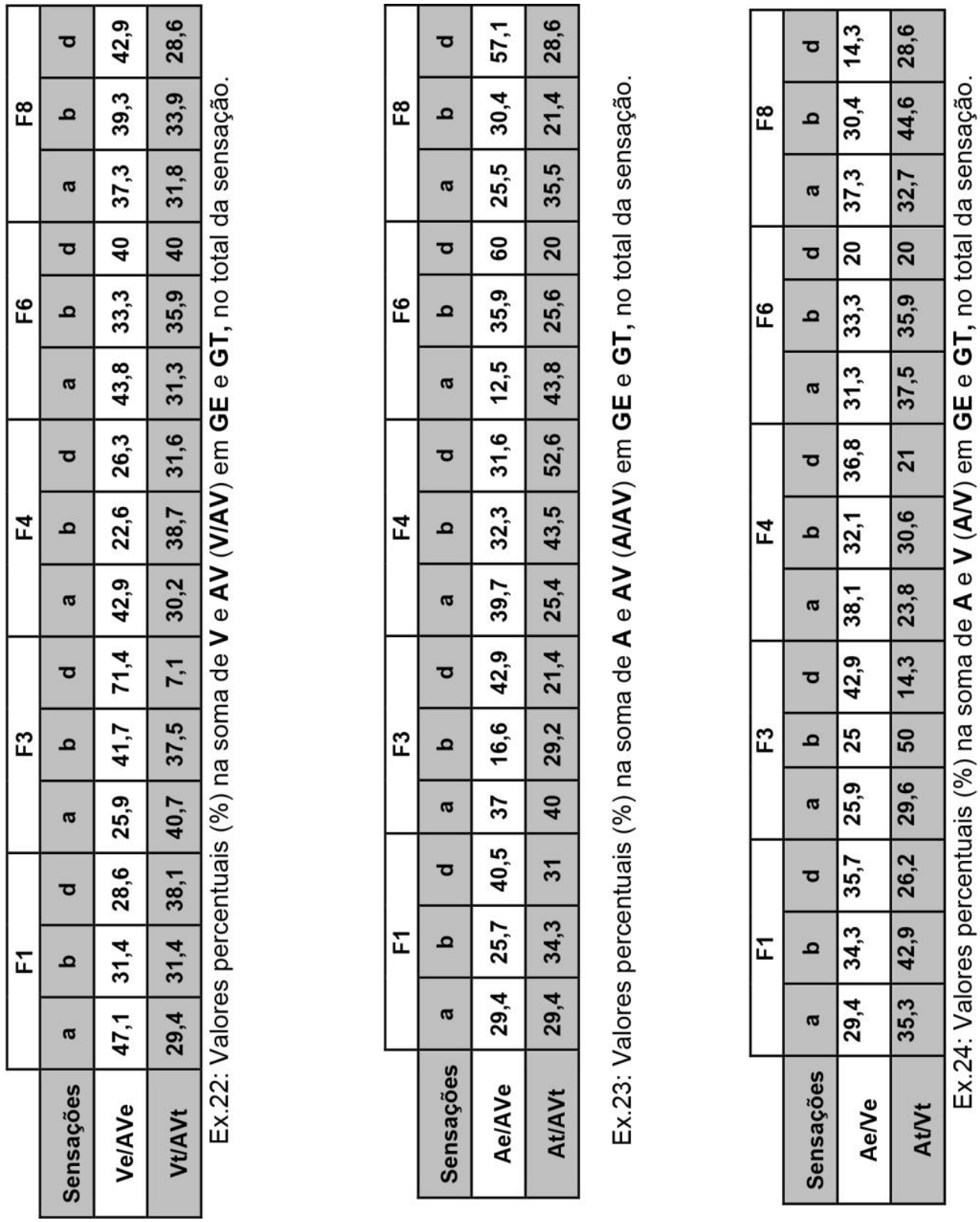

5.a) Interpretação dos índices percentuais - Uma primeira averiguação feita a partir dos dados contidos na tabela de contingência gerada pelas respostas dadas para cada estímulo e em cada fator (F) indica que, deles, os fatores F2, F5 e F7 foram os que obtiveram menor ocorrência de respostas aos estímulos, sendo ao todo 5 marcações para F5 (menos de 1\% do total) e 18 para F2 e F7 (cerca de $3,1 \%$ do total). Em comparação com F8 (180 marcações, cerca de $31 \%$ do total) ou F4 (144 marcações, 24,6\% do total), F2, F5 e F7 podem ser considerados sem muita influência para as sensações referentes aos estímulos reproduzidos e/ou gestos executados. Uma vez que esta pesquisa procurou compreender se há influência do gesto sobre a performance percussiva, focamos as nossas atenções sobre as situações onde foi possível estabelecermos uma relação de efeito dos estímulos exibidos, acerca dos dados adquiridos. Os Fatores Contextuais nas zonas dos excertos que apresentaram pertinência para as análises foram F1, F3, F4, F6 e F8. Observemos a seguir uma avaliação com uma abordagem descritiva 
das respostas dadas para cada estímulo e em cada fator $(F)$, em termos percentuais.

- Comparação por sensação e fator (F) aliando todos os estímulos, em:

i. F1: Observando a matriz da APD percebemos que a sensação de continuidade prevalece em F3, F4, F6 e F8, perdendo peso para suspensão e conclusão apenas em F1. Em verdade, a sensação de conclusão obteve maior peso apenas em $\mathrm{F} 1 \quad(44,7 \%$ das marcações, contra $37,2 \%$ de suspensão e $18,1 \%$ de continuidade), perdendo para as outras duas sensações nos restantes dos fatores analisados. Há de se destacar que F1 representou ausência de intervenção sonora do intérprete, ou seja momentos onde o percussionista não esteve atuando, de forma direta ou indireta, sobre o instrumento.

ii. F3 e F4: A sensação de continuidade obteve ligeira vantagem sobre suspensão. Poderíamos mesmo dizer que em F4 ocorreu um "empate" com $43,8 \%$ das marcações para continuidade e $43,1 \%$ para suspensão. Em F3 a diferença aumenta um pouco, mas também podemos dizer que as respostas sobre essas duas sensações foram bastante equiparadas, ficando continuidade com $41,5 \%$ das marcações contra $36,9 \%$ de suspensão.

iii. F6: Nesse fator a sensação de suspensão teve ampla vantagem em relação às outras sensações, figurando com $65 \%$ das respostas contra $26,7 \%$ de continuidade e $8,6 \%$ de conclusão. Esse fator representou, dentre outras características, a duração de execução da nota tocada (nesse caso o seu prolongamento através do rulo). Percebemos que esse atributo técnico em conjunção com as outras características atribuídas a esse fator pode ser um agente atenuante no despertar dessa sensação prevalente.

iv. F8: Certificando a nossa análise quanto ao significado de F8 nos trechos exibidos e, ao visualizarmos os resultados em termos percentuais $(61,1 \%$ para continuidade, $31,1 \%$ para suspensão, $7,8 \%$ para conclusão), percebemos que esse Fator Contextual condiz com as nossas impressões e as percepções dos participantes do experimento. As 110 marcações para continuidade mostram uma discrepância em relação aos outros fatores e demais sensações. Há de se destacar a exata igualdade de ocorrências de respostas, aliando todos os estímulos, para GE e GT para as sensações de continuidade e suspensão (55 marcações, ou seja $50 \%$ para cada gesto). Tendo a sensação de conclusão significado ínfimo com 14 marcações (sendo as ocorrências sobre GE e GT em 57,5\% e 42,5\%, respectivamente), podemos admitir que pela igualdade das respostas em GE e GT, para os trechos em que não existem momentos bruscos de "ruptura", "quebra", "tensão", etc., o tipo de gesto utilizado pelo percussionista não vem influenciar as sensações dos trechos executados, existindo pouca relevância para a sensação de conclusão.

- Comparação por sensação de $\mathbf{A}$ em relação a $\mathbf{V}$ e $\mathbf{A V}$ em: 
i. F1: A sensação de continuidade perde peso sobre o estímulo $\mathbf{A}$ em relação aos estímulos V e AV. Observamos $23,5 \%$ das ocorrências para o primeiro, enquanto anotamos $41,2 \%$ para o segundo e $35,3 \%$ para o terceiro. Por outro lado, analisando a sensação de conclusão, o estímulo A aparece com 33,3\% das marcações contra $28,6 \%$ de $\mathbf{V}$ e $38,1 \%$ de $\mathbf{A V}$. Para a sensação de suspensão o estímulo auditivo aparece com $37,1 \%$ das respostas contra $40 \%$ de $\mathbf{V}$ e $22,9 \%$ de AV. É possível constatarmos já, através desses resultados, certa relevância dos estímulos $\mathbf{V}$ e $\mathbf{A V}$ para a sensação de seguimento dos excertos exibidos quando o intérprete não intervém sonoramente no instrumento (ou seja, quando o corpo do percussionista está em movimento sem produzir sons), uma vez que $\mathbf{A}$ aparece com menos peso em continuidade. Mesmo quando comparamos apenas as respostas assinaladas dentro de cada estímulo percebemos que, em $\mathbf{A}$, a sensação de continuidade obteve apenas $12,9 \%$ das marcações contra $20 \%$ quando observamos AV de forma isolada e $21,1 \%$ quando observamos $\mathbf{V}$.

ii. F3: O estímulo A apresenta $33,3 \%$ das marcações em continuidade contra $44,4 \%$ para AV e $22,2 \%$ para V. Para as outras sensações A aparece com menores índices em relação aos outros dois estímulos. Em suspensão, o estímulo V predomina com $54,2 \%$ das respostas seguido de e, em conclusão, AV aparece em primeiro plano com $42,9 \%$ contra $35,7 \%$ de $\mathbf{V}$ e $21,5 \%$ de $\mathbf{A}$. De forma isolada, o estímulo $\mathbf{A}$ é mais influente que $\mathbf{V}$ em continuidade, mas sendo menos ocorrente que AV nessa sensação. Por esse Fator Contextual observamos como o estímulo V interfere bruscamente na sensação de suspensão quando o que está em evidência são as discrepâncias de intensidade sonora. A postura do corpo do intérprete poderá ser um agente causador desses resultados. Em F3, A sempre perde peso em relação a pelo menos um dos estímulos que tem incorporado o aspecto visual (V ou AV), o que não ocorre necessariamente com $\mathbf{V}$.

iii. F4: $O$ estímulo A causou menor influência para a sensação de continuidade ( $27 \%$ contra $34,9 \%$ de V e $38,1 \%$ de AV). Porém, na sensação suspensão, A exerce maior influência $(38,7 \%$ contra $37,1 \%$ de AV e $24,2 \%$ de V). Para a sensação de conclusão o estímulo A segue obtendo maior índice de respostas (42,1\%), o mesmo que para $\mathbf{A V}$, contra 15,8\% de V. Deste Fator Contextual podemos atestar o fato de que a falta de visibilidade da performance vem induzir no espectador a uma maior tendência à interpretação de momentos musicais sem prosseguimento, mas com características de "ruptura", "quebra", etc.

iv. F6: Para a sensação de continuidade o estímulo A segue contando com menor influência em termos percentuais obtendo $25 \%$ das respostas contra $43,7 \%$ de $\mathbf{V}$ e $31,2 \%$ de $\mathbf{A V}$. Nesse fator, curiosamente, $\mathbf{A}$ iguala-se a $\mathbf{V}$ em conclusão (20\% para cada contra $60 \%$ de AV) e ao estímulo AV em suspensão (30,8\% contra 38,5 de V). Da mesma forma que em F3 o estímulo V foi mais acionado na sensação de suspensão, mas aparece também predominante em continuidade. Dentre os Fatores Contextuais analisados as 
respostas para a sensação de conclusão em F6 apontaram a maior disparidade em termos percentuais entre AV e os outros estímulos.

- Relação por sensação de A + V (A/V) ou A + AV (A/AV) para:

i. F1, F4 e F6 em continuidade: A APD nos indica que nesses três Fatores Contextuais o estímulo A, somado a qualquer um dos outros dois estímulos, segue sendo menos influente para essa sensação. Desta forma podemos interpretar que nesses fatores, em relação ao estímulo $\mathbf{A}$, os estímulos $\mathbf{V}$ e AV (conjuntamente ou em separado) possuem maior influência na ativação de continuidade. Basta percebermos que se, em F1, AV for o ponto em comum para A e para V (A/AV e V/AV), o estímulo auditivo exercerá menor influência que o visual para essa sensação. O mesmo ocorre em F4 e F6.

ii. F3 em continuidade: Contrariando os fatores F1, F4 e F6, a soma dos estímulos $\mathbf{A}$ e $\mathbf{A V}$, exerce maior influência nessa sensação do que $\mathbf{V}+\mathbf{A V}$ (V/AV). No entanto A/V perde peso nessa sensação para V/AV.

iii. F1 e F4 em suspensão: O estímulo A somado ao V vem exercer maior influência do que qualquer outra combinação de estímulos para F1. Em F4, A surge como estímulo chave, uma vez que a soma do mesmo com $\mathbf{V}$ ou AV gera uma combinação de estímulos predominante sobre a sensação de suspensão.

iv. F3 e F6 em suspensão: A só aparecerá em maior evidência somado ao estímulo visual, uma vez que o estímulo predominante nessa sensação, em F3 e F6, é V. De outra forma, a soma de A com AV perde peso.

v. F1, F3, F4 e F6 em conclusão: Em termos percentuais a soma A/AV supera A/V em todos esses fatores. Nos fatores F1 e F3 A/V também não supera a influência V/AV. Já em F4 os pontos percentuais para essas duas últimas somas de estímulos, nessa sensação, são exatamente iguais. A igualdade percentual aparecerá para A/AV e V/AV em F6.

- Comparação por sensação de GT e GE sobre os estímulos V+ AV (V/AV) em:

i. F1: Do total de respostas atribuídas na sensação de continuidade, foram dadas $76,5 \%$ das marcações, sendo que $47,1 \%$ a GE e $29,4 \%$ a GT. Para a sensação de suspensão as respostas foram as mesmas, 31,4\%, para GE e GT. No que diz respeito às sensações de conclusão, o estímulo GT foi mais acionado possuindo $38,1 \%$ contra $28,6 \%$ de GE. Aqui, observamos como 0 gesto corporal teve efeito nas respostas, com maior tendência para a sensação de continuidade para GE, quando o corpo exerce maior deslocamento e movimento no espaço. Para a sensação de conclusão as respostas tenderam mais para $\mathbf{G T}(38,1 \%$ contra $28,6 \%$ de $\mathbf{G E})$. 
ii. F3: Das respostas atribuídas à sensação de continuidade $(66,6 \%)$, GT obteve $40,7 \%$ das marcações contra $25,9 \%$ de GE. Na sensação de suspensão (79,2\% das respostas) GE prevalece, com uma pequena margem de diferença, surgindo com $41,7 \%$ em relação a GT que aparece com $37,5 \%$. A grande prevalência de GE ocorre na sensação de conclusão onde o mesmo indica $71,4 \%$ das marcações, ao passo que GT detém 7,1\%. Contrariando as análises sobre os outros Fatores Contextuais em relação a V/AV o GT foi mais influente na sensação de continuidade, e o GE surge como mais preponderante nas outras sensações com amplo predomínio em conclusão.

iii. F4: Para V/AV, foram acionadas na sensação de suspensão $61,3 \%$ das marcações enquanto que conclusão recebeu $57,9 \%$ e continuidade $73,1 \%$. O GE influenciou 42,9\% das marcações em continuidade, contra $30,2 \%$ de GT. Para suspensão GT obteve $38,7 \%$ das respostas contra $22,6 \%$ de GE. Em conclusão GT recebeu $31,6 \%$ das marcações contra $26,3 \%$ de GE. Observando as relações entre gesto e estímulos ocorridos em F1 e F4, somos levados a concluir que, a princípio, GE vem obtendo através dos estímulos V e AV um maior grau de influência sobre a sensação de continuidade, ao passo que na sensação de suspensão e conclusão o GT "equilibra" esse domínio.

iv. F6: O estímulo V/AV surge no total com $75 \%$ das marcações em continuidade. O gesto GE predomina nessa sensação figurando com 43,7\% das respostas contra $31,2 \%$ de GT. Destacamos a exata igualdade de pontos percentuais para a sensação de conclusão, 40\% para cada. Ademais, a sensação de suspensão também obteve percentagens bastante próximas sendo $35,9 \%$ para GT contra $33,3 \%$ de GE. O GE volta a ser mais influente na sensação de continuidade nesse fator, ao passo que para as outras sensações ocorre, entre os tipos de gesto, um equilíbrio pouco observado em relação aos outros Fatores Contextuais.

6. Impressões finais - Neste artigo pudemos constatar que o aspecto visual (na forma de estímulo $\mathbf{V}$ ou $\mathbf{A V}$ ) predominou nas sensações de continuidade. Já o estímulo $\mathbf{A}$ apareceu com menores índices, para AV ou para $\mathbf{V}$, nessa sensação a partir dos Fatores Contextuais analisados. O aspecto auditivo pareceu influenciar mais as sensações de suspensão e conclusão, chegando mesmo a predominar em algumas situações.

Sobre as comparações realizadas entre o gesto expressivo (GE) e gesto técnico (GT) nos estímulos V/AV, observamos uma predominância do primeiro em relação ao segundo para as sensações de continuidade em F1, F3, F4, F6 e F8, perdendo peso apenas em F3. Por sua vez o GT determinou os pontos com maior probabilidade para sensações de conclusão em F1 e F4, obtendo a mesma percentagem que GE em F6. É curioso como esses dois gestos inverteram os sentidos de influência apenas em F3, o que nos leva a crer que o material musical apresentado também poderá ser um agente causador dessa mudança de sentido dos estímulos e gestos em relação às sensações ocorridas. Lembramos que F3 significou, nos excertos, mudança brusca de dinâmica. Em verdade esse fator, na 
APD, pareceu desestabilizar um pouco o rumo dos resultados que foram se apresentando, de forma coerente, fator por fator e sensação por sensação.

Vale a pena destacar a proximidade das respostas entre GE e GT (para V/AV) na sensação de suspensão. Em F1 a percentagem foi exatamente a mesma (31,4\%). Em F3 e F6 a diferença foi mínima, não sendo relevante uma vez que GE prevalece em F3 e GT em F6, equilibrando as impressões de influência sobre essa sensação. Apenas em F4, na sensação de suspensão o GT prevaleceu sobre o GE.

Mesmo o estímulo A apresentando, na sua maioria, menores níveis de influência para as sensações de continuidade nos fatores analisados, admitimos não termos considerado aqui uma correlação entre GE e GT desse estímulo em específico. No entanto, esses dados poderão ser utilizados para uma próxima discussão que tenha como um dos principais objetivos a identificação dos índices de influência sobre sensações de continuidade, suspensão e conclusão, independentemente das predominâncias dos estímulos. Isso acarretará também reconhecer as causas (musicais e/ou extra musicais) que possam vir a determinar esses níveis e/ou presenças dos estímulos nas sensações, em relação aos diferentes gestos executados. Apesar de não ter sido uma situação constante, não foram poucos os momentos onde a relação de um tipo de atitude do gesto (GE ou GT) reproduzido com a sensação acionada no experimento, condisseram com as ocorrências na APD.

Apesar de os excertos apresentados serem de curta duração (média de $40 \mathrm{~s}$.), chamou-nos a atenção o fato de o seccionamento feito por distintos elementos expressivos (aos quais denominamos Fatores Contextuais) gerarem também diferentes níveis de sensações sobre os estímulos reproduzidos. Afirmamos isso com base em que, no momento de mudança de Fator Contextual, as respostas variaram na relação $\mathbf{G E} / \mathbf{G T}$ e nas relações dos estímulos $\mathbf{A}, \mathbf{V}$ e $\mathbf{A V}$. Quando foram reproduzidos estímulos com a mesma atitude gestual, em distintos pontos do excerto (com fatores contextuais diferentes), houveram diversos momentos em que as respostas não seguiram o mesmo caminho. Ora, se em determinados momentos do experimento o gesto e o estímulo foram os mesmos para momentos expressivos diferentes e, além disso, as respostas não acompanharam a mesma influência, admitimos existir no Fator Contextual um certo grau de efeito sobre as sensações que o indivíduo captou nas performances apresentadas.

A APD evidenciou a influência dos movimentos corporais sobre as sensações de continuidade, suspensão e conclusão de um indivíduo numa performance específica em percussão. Outrossim, aconselhamos que o percussionista não se baseie apenas na relação audiovisual em sua performance. O mesmo também deverá ter atenção à interpretação dos meios expressivos e de conteúdo musical que a obra lhe oferece para serem explorados. Ou seja, preocupar-se com a música em si. O corpo deverá funcionar como um agente auxiliador no processo de transmissão de sensações decorrentes da performance musical apresentada. 


\section{Referências}

BOUENARD, A., M. WANDERLEY e S. GIBET (2011). "Analysis of Timpani Preparatory Gesture Parameterization”. McGill University 2009 [consultado a 26/10 2011]. Disponível em http://hal.archives-ouvertes.fr/hal-00369241/en/.

BERNARD-MÂCHE, F. (1982). Phènix. Paris: Editions Durand.

CHAIB, F. (2012). O Gesto na Performance em percussão: Uma abordagem Sensorial e Performativa. Tese de Doutorado. Departamento de Comunicação e Arte da Universidade de Aveiro.

(2012) "Três Perspectivas Gestuais para uma Performance Percussiva: Técnica, Interpretativa e Expressiva". Per Musi, Belo Horizonte, n-27. p.159-181.

DAHL, S. (2000). "The Playing of an Accent - Preliminary Observations from Temporal and Kinematic Analysis of Percussionists". Journal of New Music Research n.29 vol.3: 225233.

(2004). "Playing the Accent - Comparing Striking Velocity and Timing in an Ostinato Rhythm Performed by Four Drummers". Acta Acustica n.90: 762-776

(2005). On the beat: Human movement and timing in the production and perception of music. PhD Thesis, KTH Computer Science and Communication, KTH School of Computer Science and Communication, Stockholm.

GODØY, R. (2011) "Co-articulated Gestural-sonic Objects in Music". In. New Perspectives in Music and Gesture. SEMPRE. MPG Books Group. UK.

GODØY, R., e M. LEMAN. (2010). Musical Gestures - Sound, Movement, and Meaning. New York: Routledge.

LERDHAL, F., e R. JACKENDO. (1983). A Generative Theory of Tonal Music. Massachusetts: The Massachusetts Institute of Technology.

McGurk, H. e MacDonald, J. W. (1976) "Hearing lips and seeing voices". Nature, 264:7 46-748.

PENNA, A.G 2000. Introdução ao Gestaltismo. Coleção Introdução à Psicologia. Rio de Janeiro: Imago.

SCHUTZ, M. e S. LIPSCOMB. (2004). "Influence of Visual Information On Auditory Perception Of Marimba Stroke Types." ANAIS do VIII International Conference of Music Perception and Cognition (ICMPC8), s/p. Evanston. 2007. "Hearing gestures, seeing music: Vision influences perceived tone duration". Perception n.36: 888-897.

SALDAÑA, H. M. e ROSENBAUM, L. D. (1993). "Visual influences on auditory pluck and bow judgments". Perception \& Psychophysics, 54(3): 406-416.

SMITH, S. A. (1941) Suite for Drums. New York: Fillmore Music House.

WANDERLEY, M., B. VINES, N. MIDDLETON, C. MACKAY, e W. HATCH. (2005). "The Musical Significance of Clarinetists' Ancillary Gestures: An Exploration of the Field". Journal of New Music Research n.34: 97-113.

YOST, W. A. (2000). Fundamentals of Hearing. 5a ed. Maryland Heights: Academic Press, Elsevier.

\section{Literatura recomendada}

CATALÃO, J.(2008). Le Jeu organique du musicien: Des chemins pour une interprétation vivante en musique. Tese de Doutorado, Faculté de Musique Université de Montréal, Montréal.

CHAIB, F. e J. CATALÃO. (2011). A influência do gesto na performance percussiva apresentação de uma metodologia. Atas do Performa'11. Universidade de Aveiro: Aveiro.

CHAIB, F., J. CATALÃO e H. CHAIB FILHO. (2012). "A influência do gesto em percussão: abordagem performativa a partir de resultados preliminares de um experimento sensorial". ANAIS do VIII Simpósio de Cognição e Artes Musicais (SIMCAM 8) 238-252. CEART/UDESC: Florianópolis.

GRITTEN, A., e E. KING. (2010). Music and Gesture. 3a ed. Farnham: Ashgate . (2011). New Perspectives on Music and Gesture. Farnham: Ashgate.

LEPPERT, R. 1993. The Sight of Sound - Music, Representation and the History of the Body. California: University of California Press.

TINDALE, A., A. KAPUR, G. TZANETAKIS, P. DRIESSEN, e A. SCHLOSS. 2005. A Comparison 
of Sensor Strategies for Capturing Percussive Gestures. Vancouver, 2005.

TINDALE, A., A. KAPUR, G. TZANETAKIS, e I. FUJINAGA. Retrieval of percussion gestures using timbre classification techniques. Universitat Pompeu Fabra.

VINES, B., M. WANDERLEY, R. NUZZO, D. LEVITIN, e C. KRUMHANSL. 2004. "Performance Gestures of Musicians: What Structural and Emotional Information do they convey?" Lecture Notes in Computer Science 2915: 04.

Fernando Chaib é Doutor e Mestre em Música/Performance pelo Departamento de Comunicação e Arte da Universidade de Aveiro (Portugal) e graduou-se em percussão pela UNESP. Possui prêmios como solista e camerísta em países como Itália, Portugal e Brasil. Vem atuando nos continentes asiático, europeu e americano. Tem artigos nos principais periódicos especializados em música no Brasil e em congressos no exterior. Atualmente é professor no Instituto Federal de Goiás, onde coordena o Núcleo de Excelência para o Ensino, Pesquisa e Performance em Percussão - NEP/IFG (que integra o Centro de Excelência para o Ensino, Pesquisa e Performance em Percussão - $C \equiv P^{3}$ ).

João Catalão é Doutor em Música/Performance pela Universidade de Montreal (Canadá), tendo se especializado no Conservatório de Estrasburgo e graduado na UFSM. E membro dos grupos de percussão KT-Z (Brasil) e Sixtrum (Canadá). Atua em países do continente europeu e americano.

Homero Chaib Filho é Doutor em Matemática Aplicada pela Escuela Técnica Superior de Ingenieros Agrónomos de la Universidad de Madrid (Espanha), além de pesquisador aposentado pela EMBRAPA. Realizou comunicações em congressos nos continentes europeu, asiático e americano. Possui publicações nacionais e internacionais.

\footnotetext{
${ }^{1}$ Este artigo é parte do Capítulo 3 da Tese de Doutorado de Fernando Chaib intitulada O Gesto na Performance em Percussão: Uma Abordagem Sensorial e Performativa, defendida no Departamento de Comunicação e Arte da Universidade de Aveiro. Aveiro.

2 Núcleo de Excelência para o Ensino, Pesquisa e Performance em Percussão do Instituto Federal de Educação, Ciência e Tecnologia de Goiás.

${ }^{3}$ Núcleo de Excelência para o Ensino, Pesquisa e Performance em Percussão do Instituto Federal de Educação, Ciência e Tecnologia de Goiás.

${ }^{4} \mathrm{~A}$ discussão sobre esse experimento dá-se no tópico 4. Elaboração do Experimento "Sensação de continuidade de um trecho musical.

${ }^{5}$ Atitude aqui será o modo e o contexto em que o gesto é utilizado na performance.

${ }^{6}$ Chamaremos de ausência de intervenção sonora os momentos onde não há atuação direta do intérprete percussionista sobre os eventos sonoros (ou de "silêncio") ocorrentes em uma performance musical (pausas, ocasiões específicas de suspensões, ataques de notas com figuras rítmicas longas, etc.).

${ }^{7}$ Para uma leitura mais aprofundada sobre esse tipo de experimentação sugerimos: SAGIV, N. e WARD, J. 2006. "Cross modal Interaction: lessons from synaesthesia". Progress in Brain research. Vol.155. Amsterdam: Elsevier B.V.

8 Apresentamos 0 vídeo desse experimento, com os estímulos, em comunicação oral no Performa'11 - Encontros em Investigação em Performance 2011 (DeCA - UA), indagando aos presentes sobre quantas sílabas os mesmos conseguiam perceber. Apesar de não ter sido levantada a questão de quais fonemas eram escutados, a grande maioria das respostas apontaram para a sensação de três fonemas diferentes.

${ }^{9}$ Uma leitura mais aprofundada sobre esta matéria poderá ser encontrada em: RAMSAY, J. E SILVERMAN, 1997. B. W Functional Data Analysis. Berlim: Springer.

${ }^{10}$ Esta medida tem a ver com o próprio programa Max MSP. O programa obtém os dados de tempo no formato Quick Time e automaticamente os converte para mstime.
} 


\begin{abstract}
${ }^{11}$ Neste artigo as sensações serão representadas nas tabelas pelas letras, uma vez que a configuração deste documento dá-se em preto e branco, impossibilitando o reconhecimento das cores. Originalmente as respostas na régua surgem coloridas (verde, amarelo e vermelho). ${ }^{12}$ Com exceção ao Fator Contextual 8 (F8), todos os Fatores Contextuais buscam um sentido antagônico ao de continuidade, e fazem conexão com pelo menos um dos quatro parâmetros do som: Timbre, Altura, Tempo e Volume (ver Ex.12).
\end{abstract}

